\title{
Sun-Induced Fluorescence as a Proxy of Primary Productivity across Vegetation Types and Climates
}

\author{
Mark Pickering, Alessandro Cescatti, and Gregory Duveiller \\ European Commission Joint Research Centre, Ispra, Italy.
}

Correspondence: Mark.Pickering1@ext.ec.europa.eu, Alessandro.Cescatti@ec.europa.eu, GDuveiller@bgc-jena.mpg.de

\begin{abstract}
.
Sun-induced chlorophyll fluorescence (SIF) retrieved from satellites has shown potential as a remote sensing proxy for gross primary productivity (GPP). However, to fully exploit the potential of this signal, the robustness and stability of the SIF-GPP relationship across vegetation types and climates must be assessed. For this purpose, current studies have been limited by the availability of SIF datasets with sufficient spatial resolution to disentangle the signal between different vegetation cover types. To overcome this limitation our analysis uses GOME-2 SIF retrievals, downscaled to a resolution of $0.05^{\circ}(\sim 5 \mathrm{~km})$ to explore the relationship between SIF and FLUXCOM GPP $\left(\mathrm{GPP}_{\mathrm{FX}}\right)$, a data-driven dataset of primary productivity obtained by upscaling flux-tower measurements. The high resolution of the downscaled SIF ( SIF $_{\mathrm{DS}}$ ) dataset allows the relationships to be broken down by vegetation cover for separate climate zones, thus enabling a confrontation between GPP and SIF at fine granularity, and the comparison and categorisation of vegetation covers based on the $\mathrm{SIF}_{\mathrm{DS}}-\mathrm{GPP}_{\mathrm{FX}}$ response. This analysis first investigates the spatial and temporal relationships between FLUXCOM GPP and downscaled SIF at a global scale. Divergences and convergences between the two datasets are explored to see where high-resolution SIF can enhance our understanding of GPP. A reasonably strong linear relationship is generally observed between $\mathrm{SIF}_{\mathrm{DS}}$ and $\mathrm{GPP}_{\mathrm{FX}}$ in all vegetation categories, and an analysis of covariance (ANCOVA) shows that the spatial response is similar between certain plant traits, with some exceptions, such as equatorial broadleaf forests, and continental needleleaf forests, and distinction between woody and herbaceous vegetation. The temporal relationship between $\mathrm{SIF}_{\mathrm{DS}}$ and $\mathrm{GPP}_{\mathrm{FX}}$, within a growing season, is shown to be the strongest, followed by the spatial relationship and finally the $\mathrm{SIF}_{\mathrm{DS}}-\mathrm{GPP}_{\mathrm{FX}}$ trend between growing seasons. Whilst a linear spatial relationship is generally observed between $\mathrm{SIF}_{\mathrm{DS}}$ and $\mathrm{GPP}_{\mathrm{FX}}$ in all vegetation categories, geographical regions of non-linearity suggest where $\mathrm{SIF}_{\mathrm{DS}}$ could potentially provide information about ecosystem dynamics that are not represented in the FLUXCOM GPP dataset. With the demonstration of downscaled SIF as a proxy for GPP, the response of SIF $_{\mathrm{DS}}$ to short-term fluctuations in several meteorological variables is analysed, and the utility of $\mathrm{SIF}_{\mathrm{DS}}$ as a measure of environmental stress explored. For a broad range of land cover categories, the most significant environmental driving and limiting meteorological variables are determined and vegetation groupings of similar SIF-meteo response reinforce the vegetation categorisations suggested by the SIF-GPP ANCOVA. This comparative exploration of two of the most recent products in carbon productivity estimation shows the value in downscaling SIF data, provides an independent probe of the FLUXCOM GPP model, enhances our understanding of the global SIF-GPP spatio-temporal relationship with a particular focus on the role of vegetation cover, and demonstrates the utility of SIF as a measure of environmental stress.
\end{abstract}


https://doi.org/10.5194/bg-2021-354

Preprint. Discussion started: 21 January 2022

(c) Author(s) 2022. CC BY 4.0 License.

(c) (i)

\section{Introduction}

Accurately quantifying the gross primary productivity (GPP) of vegetation systems across the globe is vital for modelling the future trajectories of atmospheric carbon fluxes and making projections regarding the Earth's climate. Indeed one of the largest sources of uncertainty in the carbon cycle is represented by the interaction between atmospheric carbon dioxide, climate and terrestrial ecosystem dynamics (Friedlingstein et al., 2019; Anav et al., 2015). Photosynthesis drives this interaction, with vegetation removing carbon from the atmosphere and investing it in growth, cell maintenance and respiration. In turn, photosynthesis is regulated by environmental conditions, and as climates change, both the mean weather and its variability will change, impacting the productivity of vegetation systems (Seneviratne et al., 2012).

It is not possible to directly measure GPP at a global level, however many techniques have been developed to derive productivity at different scales using a range of data-driven or model-based approaches. Light use efficiency (LUE) models, for example, estimate GPP as a function of the absorbed photosynthetically active radiation (APAR), the efficiency of utilising light in photosynthesis $\epsilon_{\mathrm{LUE}}$ and the effect of climatic constraints, such as temperature (T) and precipitation (P):

$$
\mathrm{GPP}=\epsilon_{\text {LUE }} \times \mathrm{APAR} \times \mathrm{f}(\mathrm{T}) \times \mathrm{f}(\mathrm{P})
$$

(Ryu et al., 2019; Running et al., 2004; Zhang et al., 2017; Lee et al., 2013).

A relevant assessment based on a process-oriented ensemble, known as TRENDY, provides a model-based estimation of

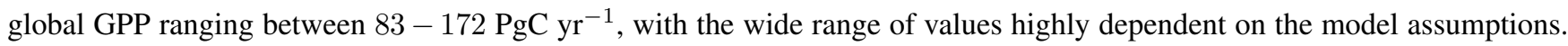
Eddy covariance sites, or flux towers, provide the most accurate ways of measuring carbon fluxes at ecosystem scale, through the systematic observation of the net ecosystem exchange of $\mathrm{CO} 2$. These measurements have been standardised and made available thanks to the FLUXNET initiative that is linking different continental networks of eddy covariance towers (Baldocchi et al., 2001). The FLUXCOM project has upscaled FLUXNET data to a global estimate of GPP using machine learning methods to integrate site-level observations, satellite remote sensing information, and meteorological data (Tramontana et al., 2016). Whilst FLUXCOM is a large step forward in estimating GPP at a global level, it is not without its limitations and uncertainties. In fact, the various FLUXCOM GPP estimates use an ensemble of different machine learning methods and data inputs, which result in a broad spread of mean global GPP estimates among the ensemble members between $108-130 \mathrm{PgC}$ $\mathrm{yr}^{-1}$. A comparative study between FLUXCOM and TRENDY finds that for $70 \%$ of the globe at least the 9 out of 16 TRENDY models fall outside the FLUXCOM range (Jung et al., 2020).

In recent years, sun-induced chlorophyll- $a$ fluorescence (SIF), retrieved from space-based instruments, has grown in use as a remotely sensed proxy for GPP, in addition to more traditional remote proxies such as spectral vegetation indices (Ryu et al., 2019; Porcar-Castell et al., 2014). This fluorescent light - resulting from the re-emission by leaves of incident photons at lower energy - is considered to be the mechanism developed by plants to respond near-instantaneously to rapid perturbations in environmental conditions of light, temperature and water availability (Frankenberg and Berry, 2017). The SIF flux can similarly be expressed in terms of the absorbed incident radiation and the efficiency with which this radiation is converted into fluorescent radiation, $\epsilon_{\mathrm{F}}$ : 
https://doi.org/10.5194/bg-2021-354

Preprint. Discussion started: 21 January 2022

(c) Author(s) 2022. CC BY 4.0 License.

(c) (i)

$$
\mathrm{SIF}=\epsilon_{\mathrm{F}} \times \epsilon_{\mathrm{esc}} \times \mathrm{APAR}
$$

where the term, $\epsilon_{\mathrm{esc}}$, accounts for the efficiency of photons to escape re-absorption and scattering by other leaves in the canopy (Lee et al., 2013). Rearranging the equations for SIF and GPP fluxes:

$$
\mathrm{GPP}=\frac{\epsilon_{\mathrm{LUE}}}{\epsilon_{\mathrm{F}} \epsilon_{\mathrm{esc}}} \times \mathrm{SIF}
$$

we see that under conditions in which the various conversion efficiencies remain constant, there is a linear relationship between SIF and GPP. Whilst at small spatio-temporal timescales, where leaf chemistry is particularly sensitive to changes in absorbed photosynthetically active radiation and the fraction of fluoresced photons escaping from the canopy, there is evidence for the divergence of SIF and GPP from linearity, it appears that the broader canopy-scale relationship smooths over these nonlinearities (Magney et al., 2020). Indeed, there is a substantial body of evidence that shows that SIF is positively correlated with leaf photochemistry, exhibiting a generally linear relationship in both space and time, and across spatio-temporal scales (Zhang et al., 2016; Sun et al., 2018; Magney et al., 2020). However, this SIF-GPP relationship may exhibit some dependency on the vegetation type, for example through the canopy structure that is affecting $\epsilon_{\mathrm{esc}}$, as well as the leaf photochemical properties and external conditions, for example climate drivers. Due to the relatively fast response of SIF and close link to leaf photochemistry, compared to other remote indicators of greenness, such as NDVI, SIF has the potential to be an indicator of environmental stress for the plant photosystem (Walther et al., 2019; Jiao et al., 2019).

There is currently no orbiting satellite designed explicitly to directly measure SIF from space. The first that will do so is the exploratory mission FLEX, scheduled for launch in 2023 (Coppo et al., 2017). In the meanwhile, SIF has been retrieved from other instruments designed for measuring the atmosphere greenhouse gas concentration, namely GOSAT, SCIAMACHY, the Global Ozone Monitoring Experiment-2 (GOME-2), the Orbiting Carbon Observatory 2 (OCO-2) and the TROPO-spheric Monitoring Instrument (TROPOMI). However, several issues hamper the use of these data for the quantification of terrestrial GPP. First, some instruments (GOSAT, OCO-2) are sampling the surface, leaving wide gaps between different satellite overpasses. Second, the time series of observations is shorter than desired for carbon science, especially for the more recent instruments (e.g. OCO-2 and TROPOMI). Third, most have a spatial resolution that is too coarse to isolate homogeneous vegetation patches of distinct land cover types.

Efforts have been made to improve the resolution and coverage of SIF datasets by combining SIF data with other high resolution remote sensing data (Gentine and Alemohammad, 2018; Li and Xiao, 2019; Zhang et al., 2018a; Yu et al., 2018). These approaches generally rely on statistical inference, through machine learning methods. A recent downscaling methodology, based on a light use efficiency model, combines the GOME-2 data with several explanatory biophysical variables in a process oriented scheme. The resulting dataset has a spatial resolution of $0.05^{\circ}(5 \mathrm{~km})$ and is therefore at a scale relevant to studies of land cover at global scale (Duveiller et al., 2020; Duveiller and Cescatti, 2016). This model ensures that the downscaling method is grounded on a biophysical theory whilst also preserving the GOME-2 signal. Downscaling the SIF in this way results in a high resolution dataset with a reasonably long archive, improving accuracy in the exploration of the SIF relationship with vegetation cover. 
https://doi.org/10.5194/bg-2021-354

Preprint. Discussion started: 21 January 2022

(c) Author(s) 2022. CC BY 4.0 License.

(c) (i)

If downscaled sun-induced fluorescence is to be used as a proxy for ecosystem productivity or as a measure of environmental stress, it is important to understand the spatial and temporal relationships between SIF and the current state-of-the-art GPP datasets at a global scale, and in particular understand how they deviate for differing vegetation covers and climate zones. To this end, this paper serves several purposes. Firstly, the analysis provides a thorough test of the utility of the downscaling method to reproduce known SIF-GPP patterns, in particular through the spatio-temporal correlation between downscaled SIF and FLUXCOM GPP. Exploring variations in the FLUXCOM GPP with an independent SIF dataset, often likewise regarded as a proxy to GPP, helps to probe its strengths and limitations through areas of coherence and divergence. Second, as a global, high-resolution investigation into the SIF-GPP relationship, the analysis allows us to learn more about the differing spatial linear relationship between SIF and GPP and their variation in nature with a particular focus on similarities and differences between vegetation covers. This allows the determination of which vegetation covers have a similar SIF-GPP response, and for which vegetation covers care should be taken in the use of SIF as a proxy for GPP. Finally, having established the spatiotemporal relationship between the downscaled SIF and the FLUXCOM GPP, the paper investigates the potential of downscaled SIF as a global measure of environmental stress to fluctuations in several meteorological factors, in the process determining the most significant driving and limiting meteorological factors in monthly SIF fluctuations. By utilising the high resolution of the downscaled SIF, it is possible to understand with improved confidence the extent to which vegetation cover plays a role in these relationships using dedicated techniques (e.g. Álvaro Moreno-Martínez et al., 2018).

\section{Data}

\subsection{Vegetation cover data}

The data relating to the vegetation cover of each pixel is derived from the Copernicus Climate Change Service (C3S) via the climate data store platform, with the data created by the ESA CCI program (CCI, 2017; Defourny, 2019). The land cover classes are converted to vegetation covers, as used by dynamic global vegetation models, whilst aggregating the data to a spatial resolution of $0.05^{\circ}$. The following vegetation covers are considered: grassland $=$ 'GRA', crops $=$ 'CRO', evergreen broad-leaf forest $=$ 'EBF', deciduous broad-leaf forest $=$ 'DBF', evergreen needle-leaf forest $=$ 'ENF', and deciduous needle-leaf forest $=$ 'DNF'. To ensure a high homogeneity in the selected data, the dominant vegetation type must cover at least $75 \%$ of a pixel and with no change over the considered years, 2007-2014.

\subsection{Climate classification}

The climate zone classification used in the analysis follows the Köppen-Geiger climate classification scheme (Kottek et al., 2006; Rubel and Kottek, 2010; Rubel et al., 2017). The classification maps are representative of the period 1986-2010 and are available at a spatial resolution of $0.0833^{\circ}$ which are extrapolated via binomial interpolation to grid cells (referred to hereon as pixels) of $0.05^{\circ}$. 
https://doi.org/10.5194/bg-2021-354

Preprint. Discussion started: 21 January 2022

(c) Author(s) 2022. CC BY 4.0 License.

(c) (i)

Four broad categories are considered from this scheme: equatorial, arid, temperate and continental. Equatorial contains 'Group A' climate regions: areas where each month is above $18^{\circ} \mathrm{C}$ and with high precipitation. Arid regions are 'Group B' climates: areas defined by low precipitation. Temperate regions are 'Group C' climates: with the coldest month averaging $0-18^{\circ} \mathrm{C}$ and at least one month averaging more than $10^{\circ} \mathrm{C}$. Finally, continental regions are 'Group D' climates: at least one month must average below $0^{\circ} \mathrm{C}$ and at least one month above $10^{\circ} \mathrm{C}$. Figure 1 shows the spatial distribution of the global climate groupings and the dominant vegetation cover of the pixels considered in the analysis.

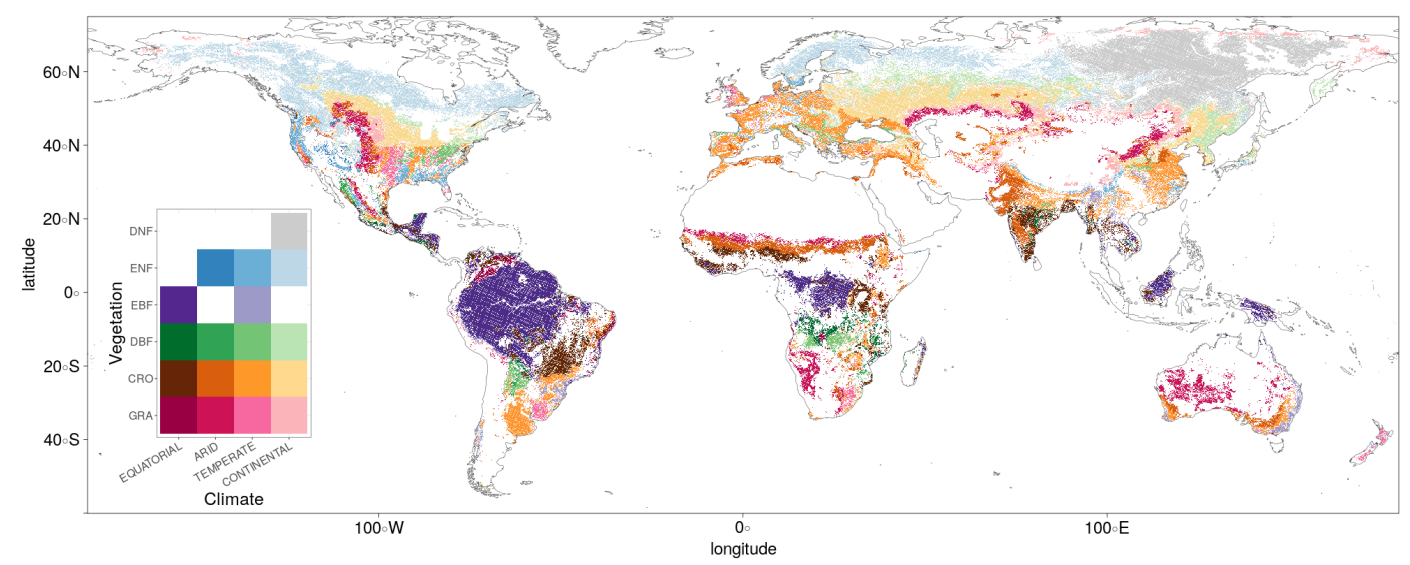

Figure 1. The dominant Köppen-Geiger climate zone and vegetation cover corresponding to each of the pixels passing the full set of selection requirements.

\subsection{Growing season data}

The Vegetation Index and Phenology (VIP) global dataset from NASA's Making Earth System Data Records for Use in Research Environments (MEaSUREs) program is used to define the growing seasons at each grid cell for each year (Didan, 2016). The datasets are created using surface reflectance data from the MODIS instrument. This data provides a consistent NDVI and EVI measurement from which to characterise the vegetation phenology. The Vegetation Index and Phenology (VIP) Phenology NDVI (VIPPHEN) v004 dataset has a global spatial resolution of $0.05^{\circ}$ and provides annual metrics on the start and length of the growing season for each pixel for the years 2000-2014.

Whilst correlation between SIF and GPP has been observed across all seasons, only the relationship between downscaled SIF and FLUXCOM GPP during the growing season of each pixel is considered in the present study (Magney et al., 2019; Bowling et al., 2018). This removes the effect of winter periods, when there is little primary productivity and when the retrieval of SIF can be problematic at northern latitudes. Off-season, the relatively weak SIF signal and the quality requirements in the downscaling process result in a dataset with gaps. Including this data in the analysis would likely result in distorted conclusions regarding average downscaled SIF signals over the time period. Additionally, only the first growing season of each year is considered in regions with multiple growing seasons. 
https://doi.org/10.5194/bg-2021-354

Preprint. Discussion started: 21 January 2022

(c) Author(s) 2022. CC BY 4.0 License.

\subsection{SIF data}

Two SIF datasets are considered in this analysis, produced via the downscaling method detailed in references Duveiller and Cescatti (2016) and Duveiller et al. (2020). The two differ in the retrieval method for obtaining the input data from the GOME2 satellite, the first product developed by Joiner et al. (2013), is referred to as SIFJJ in this document, whilst the second, developed by Köhler et al. (2015), is referred to as SIFPK. The downscaling method calibrates these input retrievals via a light use efficiency model using high resolution biophysical variables from the MODIS (MOderate Resolution Imaging Spectroradiometer) instrument of the Terra and Aqua Satellites. The optimal combination of variables is identified in combination with OCO-2 data, and the downscaled dataset is found to have a high level high spatio-temporal agreement with observations from the TROPOMI mission.

The resulting downscaled SIFPK and SIFJJ products have a spatial resolution of $0.05^{\circ}$ and a temporal separation of 8 days (with measurements averaged over a sliding window of 16 days). The datasets currently cover the timespan 2007-2017, with 46 measurements each year (with the exception of the 2007 SIF dataset, containing 44). In contrast to the coarse resolution SIF, the downscaled SIFJJ dataset is found to have a higher level of agreement with the OCO-2 data than the SIFPK dataset

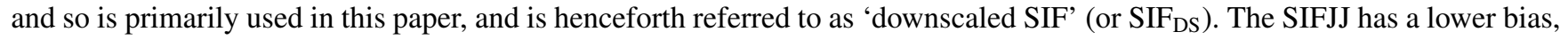
but more noise than the SIFPK, and the application of the downscaling algorithm smooths the result, resulting in a less noisy downscaled product.

To ensure high quality in the data, and compatibility with the other datasets, several requirements are placed on each pixel in each year, further to the requirements detailed in Duveiller et al. (2020), Köhler et al. (2015), and Joiner et al. (2013). There must be at least 10 instances of valid $\mathrm{SIF}_{\mathrm{DS}}$ observations of the pixel within the growing season with fewer than $40 \%$ of the expected number of $\mathrm{SIF}_{\mathrm{DS}}$ missing or invalid. There must also be least six years of valid measurements satisfying the requirements between 2007-2014. The selections ensure that the SIF signal, which is relatively weak compared to background noise, and affected by cloud coverage, is representative of the growing season as a whole as well as excluding regions with short growing seasons that may be more susceptible to fluctuations from unusual weather conditions. Requiring multiple years of data passing the quality requirements enables the investigation of temporal trends, whilst also ensuring that the measurements are representative of each pixel.

In order to reduce spatial auto-correlation and the double-counting of interpolated pixels in other datasets, pixels considered in the analysis must be separated by a two-pixel gap in all directions (Ploton et al., 2020). Each pixel is matched with the dominant vegetation cover and climate classification, as well as FLUXCOM GPP and meteorological data, passing the respective requirements. Figure 2 shows the mean downscaled SIF for the growing season of each pixel passing the analysis selection requirements, averaged over the period 2007-2014.

\subsection{GPP data}

The gross primary productivity (GPP) dataset is provided by the FLUXCOM project, measured as a daily carbon uptake [gC $\mathrm{m}^{-2}$ day $^{-1}$ ] (Jung and FLUXCOM Team, 2016; Tramontana et al., 2016; Jung et al., 2020). In the 'RS only' setup used in 
https://doi.org/10.5194/bg-2021-354

Preprint. Discussion started: 21 January 2022

(c) Author(s) 2022. CC BY 4.0 License.

(c) (i)
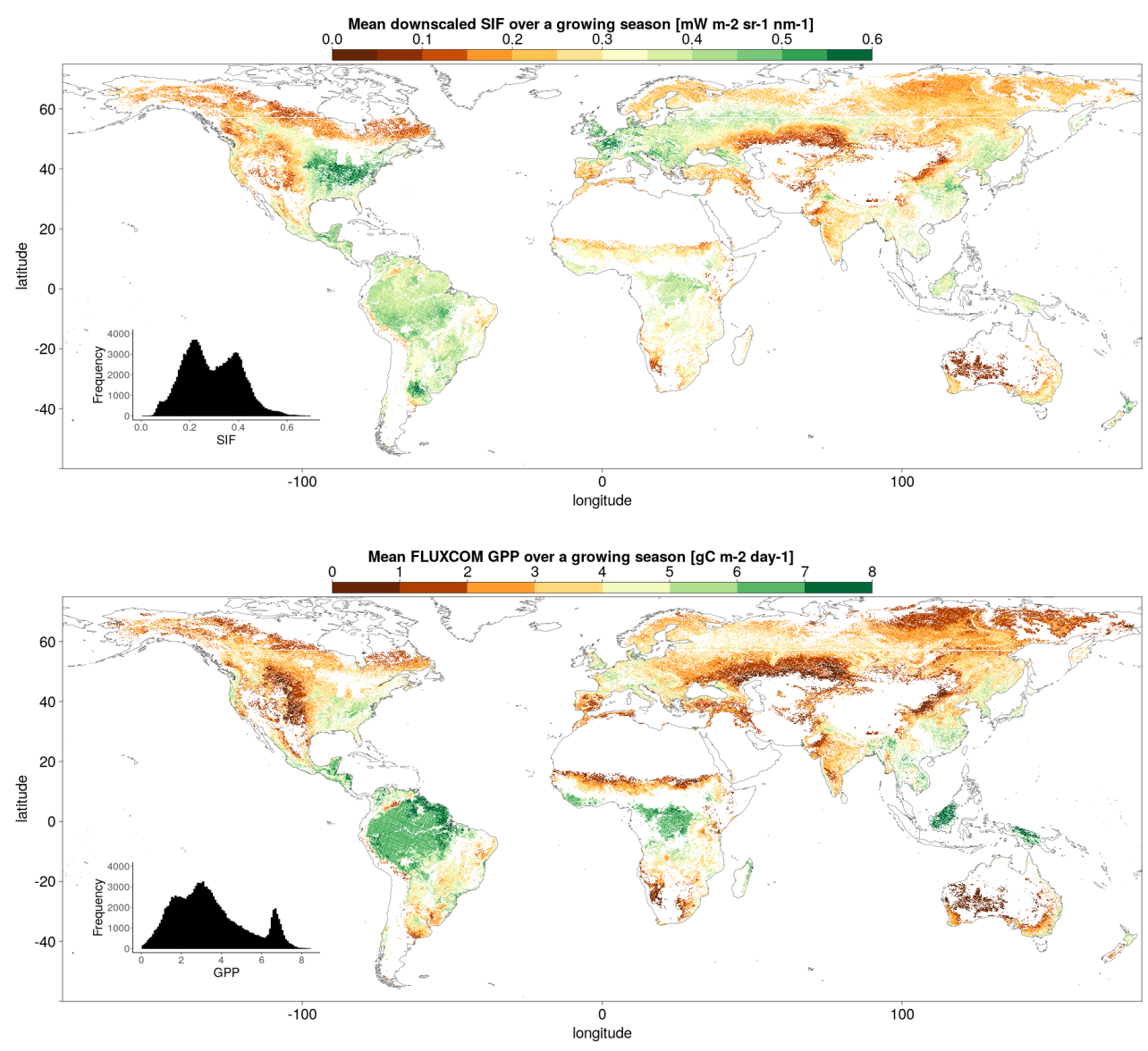

Figure 2. Mean downscaled SIF (above) and FLUXCOM GPP (below) over the growing season, corresponding to each of the pixels passing the full set of selection requirements. The $\mathrm{SIF}_{\mathrm{DS}}$ fluxes and $\mathrm{GPP}_{\mathrm{FX}}$ estimations for each pixel are averaged over multiple years between 2007 and 2014.

this analysis and described in Tramontana et al. (2016) and Jung et al. (2018), an ensemble of nine machine learning methods merge carbon flux estimations from FLUXNET eddy covariance towers with remote sensing data taken or derived from the MODIS sensor to estimate gross primary productivity across the terrestrial surface. The remotely sensed data includes land surface temperature, fraction of absorbed photosynthetic active radiation, normalized difference vegetation index, normalized difference water index and land surface water index. The resulting dataset, hereon referred to as 'FLUXCOM GPP' (or GPP $\mathrm{FX}_{\text {), }}$ consists of a global estimate of GPP at a spatial resolution of $0.0833^{\circ}$. These estimates occur in timesteps of 8 days (46 over the course of a year) and cover the downscaled SIF data collection period up until the year 2016.

The GPP pixels are extrapolated via binomial interpolation to $0.05^{\circ}$ pixels in order to focus on the comparison with the SIF pixels. Figure 2 shows the FLUXCOM GPP for the growing season of each pixel passing the analysis selection requirements, averaged over the period 2007-2014. 
https://doi.org/10.5194/bg-2021-354

Preprint. Discussion started: 21 January 2022

(c) Author(s) 2022. CC BY 4.0 License.

(c) (i)

\subsection{Meteorological data}

ERA5 is the fifth generation ECMWF reanalysis global climate and weather dataset, and the ERA5-Land dataset replays the land component of the reanalysis to provide land variables at an enhanced resolution at $0.1^{\circ}$. The dataset is extrapolated via binomial interpolation to $0.05^{\circ}$ pixels in order to focus on the comparison with the $\mathrm{SIF}_{\mathrm{DS}}$ pixels, with only non-consecutive months considered, in order to reduce temporal autocorrelation.

Meteorological variables are obtained from the ERA5-Land monthly reanalysis dataset (Muñoz Sabater et al., 2021; Muñoz Sabater, 2019b). These include: air temperature ( $2 \mathrm{~m}\left[{ }^{\circ} \mathrm{C}\right]$ : temperature of air at $2 \mathrm{~m}$ ), surface net solar radiation ( $\mathrm{ssr}\left[\mathrm{J} \mathrm{m}^{-2}\right]$ : amount of solar radiation reaching the surface of the Earth minus the amount reflected by the Earth's surface) and soil moisture (swvl1 $\left[\mathrm{m}^{3} \mathrm{~m}^{-3}\right]$ : volume of water in soil layer 1, 0-7 cm, of the ECMWF Integrated Forecasting System). A variable that is not available is the mean monthly vapour pressure deficit (VPD [kPa]), the difference between the saturated vapour pressure and the actual vapour pressure (Grossiord et al., 2020). It is important in regulating the stomatal conductance of plants, and thus useful to relate to both SIF and GPP. Due to non-linearity in the vapour pressure-temperature response, the average saturated vapour pressure of each month is calculated from the average of the saturation vapour pressure at the mean daily maximum and mean daily minimum air temperatures over the course of the month, using the following formula (Allan and Pereira, 1998):

$$
e_{s}=\left[e^{\circ}\left(T_{\max }\right)+e^{\circ}\left(T_{\min }\right)\right] / 2 \text { where: } e^{\circ}(T)=0.061 \mathrm{x} \exp ^{17.27 T /(T+237.3)}
$$

The latter formula is also used in the calculation of the actual vapour pressure from the dewpoint temperature. The minimum and maximum air temperatures and the dewpoint temperature are taken from the ERA5-Land hourly reanalysis dataset (Muñoz Sabater, 2019a).

\section{Methodology}

The $\mathrm{SIF}_{\mathrm{DS}}-\mathrm{GPP}_{\mathrm{FX}}$ spatio-temporal relationship at global scale is analysed via several diagnostics. Linear models and analysis of covariance (ANCOVA) are performed to determine the similarities and dissimilarities in the response across different vegetation covers. Finally, the response of the $\mathrm{SIF}_{\mathrm{DS}}$ to fluctuations in meteorological conditions is investigated to assess the potential of this metric to diagnose the impact of environmental drivers. For the analysis, each $0.05^{\circ}$ vegetated pixel is described by time series of downscaled SIF, FLUXCOM GPP, and meteorological values, taken over the first growing season of each year between 2007 and 2014. This same set of 135,000 global pixels is used in each analysis of the current paper, with consideration given to the vegetation cover and climate zone of the pixels analysed.

\subsection{The spatio-temporal relationship of $\mathrm{SIF}_{\mathrm{DS}}$ and $\mathrm{GPP}_{\mathrm{FX}}$}

Since the processes and drivers of variability in SIF and GPP may differ in time and space, we designed an analytical framework to isolate the temporal components of the $\mathrm{SIF}_{\mathrm{DS}}-\mathrm{GPP}_{\mathrm{FX}}$ relationship at different temporal resolutions (intra-and inter-annual) from the spatial variations. The spatial component of the $\mathrm{SIF}_{\mathrm{DS}}-\mathrm{GPP}_{\mathrm{FX}}$ correlation is isolated by determining the multi-year mean $\mathrm{SIF}_{\mathrm{DS}}$ and mean $\mathrm{GPP}_{\mathrm{FX}}$ for each pixel. Here 'mean' refers to the mean daily value of the downscaled SIF or FLUXCOM 
https://doi.org/10.5194/bg-2021-354

Preprint. Discussion started: 21 January 2022

(c) Author(s) 2022. CC BY 4.0 License.

\section{(c) (i)}

GPP over the first growing season. These values are converted to a multi-year means by averaging over the period 2007-2014. The Pearson's spatial correlation coefficient, $r$, is calculated at both a global scale, as well as over a local moving window of

$2.5^{\circ}$ for each climate-vegetation category, with the latter requiring at least 10 pixels within the moving window to be assessed and reported. The temporal component of the $\mathrm{SIF}_{\mathrm{DS}}-\mathrm{GPP}_{\mathrm{FX}}$ correlation is assessed at both the inter- and intra-annual scales. The inter-annual correlation, refers to the temporal relationship between the mean growing season $\mathrm{SIF}_{\mathrm{DS}}$ and $\mathrm{GPP}_{\mathrm{FX}}$ values between consecutive years at the same location. It should be noted that a temporal degradation in the GOME-2 instruments has been observed, potentially affecting the long-term analysis of SIF trends and therefore the SIF-GPP relationship, particularly from 2015 onwards (Zhang et al., 2018b). Whilst this may have a slight impact on the analysis presented here - which uses data collected up until 2014 - we nevertheless consider the inter-annual comparison of $\mathrm{SIF}_{\mathrm{DS}}$ and $\mathrm{GPP}_{\mathrm{FX}}$ worthwhile. Meanwhile, the intra-annual correlation refers to the relationship between individual $\mathrm{SIF}_{\mathrm{DS}}$ and $\mathrm{GPP}_{\mathrm{FX}}$ values made at 8-day timesteps within a growing season, in order to determine the internal growing season statistics. The correlation at each pixel is calculated for each year considered and averaged over the multi-year time period.

\subsection{The spatial linear relationship between SIF $_{D S}$ and GPP $_{F X}$}

The same process and data used to isolate and determine the spatial component of the correlation is used to determine the global spatial linear relationships between $\mathrm{SIF}_{\mathrm{DS}}$ and $\mathrm{GPP}_{\mathrm{FX}}$. For this purpose, an area-weighted least squares linear model fits the global $\mathrm{SIF}_{\mathrm{DS}}-\mathrm{GPP}_{\mathrm{FX}}$ distribution of pixels for each climate and vegetation cover. Whilst theoretically the leaf photosynthesis may be zero when the quantity of emitted SIF radiation is zero, this does not necessarily imply that the canopy level SIF-GPP relationship extends linearly to zero, as the canopy level SIF-GPP relationship smooths over known non-linearities at finer scales and lower SIF yields (Magney et al., 2020). Additionally, forcing the linear regression through the origin based on a prior expectation (in this case that SIF and GPP are simultaneously zero) that lies outside the bounds of the considered data will introduce a bias into the regression parameters. Therefore the intercept of the $\mathrm{SIF}_{\mathrm{DS}}-\mathrm{GPP}_{\mathrm{FX}}$ relationship is not forced through zero to account for this variation, as well as potential deviations from linearity in the sampled pixels.

\subsection{Spatial analysis of covariance between SIF $_{\mathrm{DS}}$ and GPP $\mathrm{FX}$}

In order to assess and test similarities in the global $\mathrm{SIF}_{\mathrm{DS}}-\mathrm{GPP}_{\mathrm{FX}}$ response between vegetation covers, an ANCOVA (analysis of covariance) is performed. ANCOVA compares linear regressions between two or more groups whilst controlling for a covariate to test about the stastistical significance of the effects. In this specific case, the downscaled SIF covariate is controlled for in a spatial linear regression with the FLUXCOM GPP that differes between vegetation and climate groups. A comparison of the regression slope and intercept between pairs of vegetation cover groupings is conducted in terms of the significance (through the p-value) and the size of the effect (through $\eta^{2}$ ). The p-value for the slope parameter is the probability of obtaining an equal or more extreme difference in the regression slopes of two vegetation groups under the null hypothesis that the vegetation cover has no effect. The p-value for the intercept additionally assumes the null hypothesis for the regression slope. The size of the effect is measured through $\eta^{2}\left(0 \leq \eta^{2} \leq 1\right)$, the proportion of the sum of squares from the nominal grouping of vegetation cover, $S S_{v e g}$, to the overall sum of squares for the linear relationship, $S S_{l m}$ : 
https://doi.org/10.5194/bg-2021-354

Preprint. Discussion started: 21 January 2022

(c) Author(s) 2022. CC BY 4.0 License.

(c) (i)

$$
\eta^{2}=S S_{v e g} / S S_{l m}
$$

Therefore, $\eta^{2}$ gives the proportion of the variance attributable to the vegetation cover grouping and is conceptually similar to the significance of the coefficient of determination, $r^{2}$, in linear relationships. Therefore the p-value provides evidence for whether the difference in $\mathrm{SIF}_{\mathrm{DS}}-\mathrm{GPP}_{\mathrm{FX}}$ response is significant between vegetation covers, and $\eta^{2}$ can be thought of as the magnitude of that difference. For each climate grouping, pairwise ANCOVA comparisons are made between vegetation covers for a sample of 400-1000 pixels.

\subsection{Estimating global GPP with downscaled SIF}

The derived global spatial linear $\mathrm{SIF}_{\mathrm{DS}}-\mathrm{GPP}_{\mathrm{FX}}$ relationships are used to project the downscaled FLUXCOM SIF into an estimate of gross primary productivity, $\mathrm{GPP}_{\mathrm{Est}}$. This is also interpreted in terms of absolute and percentage differences to the FLUXCOM GPP, with the percentage difference calculated as:

$$
\mathrm{GPP}_{\mathrm{diff}}=100 \mathrm{x}\left(\mathrm{GPP}_{\mathrm{Est}}-\mathrm{GPP}_{\mathrm{FX}}\right) / \mathrm{GPP}_{\mathrm{FX}}
$$

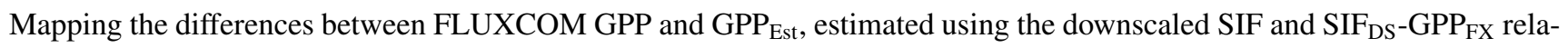
tionships, enables the display of areas where the global, category-dependent, linear relationships succeed or fail in replicating the $\mathrm{GPP}_{\mathrm{FX}}$ from the local $\mathrm{SIF}_{\mathrm{DS}}$ observations. There are three different groupings of global linear relationships used in the breakdown. Firstly the GPP estimate depends only on separate $\mathrm{SIF}_{\mathrm{DS}}-\mathrm{GPP}_{\mathrm{FX}}$ relationships for each Köppen-Geiger climate zone; secondly, both the climate zone and vegetation cover are taken into account; and finally the groupings used are suggested from the analysis of covariance. The latter is also used to display an estimate of global GPP based on the downscaled SIF, scaled by the FLUXCOM GPP relationships.

\subsection{The $\mathrm{SIF}_{\mathrm{DS}}$ response to meteorological fluctuations}

In order to explore the potential capabilities of SIF as an early indicator of stress across different type of vegetation type, the response of downscaled SIF to anomalies in a number of meteorological variables is analysed. A specific focus is given to meteorological extremes, investigated through the z-score from the long-term monthly mean, in order to determine what are the driving meteorological factors for SIF fluctuations in different climate zones. The study uses the same initial data as the investigation into $\mathrm{SIF}_{\mathrm{DS}}-\mathrm{GPP}_{\mathrm{FX}}$ response, however monthly averages of the $\mathrm{SIF}_{\mathrm{DS}}$ are taken in order to compare with the month-averaged meteorological variables. The meteorological factors considered are air temperature, solar radiation, soil moisture and vapour pressure deficit. Additionally, only non-consecutive months within a growing season are included, in order to reduce temporal autocorrelation.

For every pixel, the mean and standard deviation of the $\operatorname{SIF}_{\mathrm{DS}}$ and meteorological variables is calculated for each month over the period 2007-2014. These individual monthly values are re-expressed as a z-score for each pixel - i.e. the difference to the 2007-2014 monthly mean, standardised by the standard deviation. For comparative purposes, the FLUXCOM GPP is also included, however it should be noted that the product takes several remotely-sensed climatic variables as input to the machine learning method, including land surface temperature, fraction of absorbed photosynthetic active radiation, normalized 
https://doi.org/10.5194/bg-2021-354

Preprint. Discussion started: 21 January 2022

(c) Author(s) 2022. CC BY 4.0 License.

(c) (i)

difference water index and land surface water index, and therefore it is not fully independent of the meteorological factors, unlike the downscaled SIF.

\section{Results}

\subsection{The spatio-temporal correlation of $\mathrm{SIF}_{\mathrm{DS}}$ and $\mathrm{GPP}_{\mathrm{FX}}$}

The Pearson's correlation coefficient, $r$, between the downscaled SIF and FLUXCOM GPP is projected into figure 3, to display areas of high and low temporal and local spatial correlation. Meanwhile, figure 4 displays the global spatial and average global temporal correlations for each vegetation cover and climate zone for comparative purposes.

The first thing to note is that at a global scale, prior to the breakdown into separate climate-vegetation cover categories, there is a reasonably strong correlation between the downscaled SIF and the FLUXCOM GPP. Between different climate-vegetation groupings, however, there is variety in the strength of the correlation. Whilst the breakdown of the relationship by either climate zone or vegetation cover separately provides extra information in comparison to no breakdown, greater variability is shown from a breakdown by both categories simultaneously, highlighting the value of the downscaled SIF dataset in assessing the relationship with GPP across vegetation categories in different climates. The slight variation in correlation across different vegetation covers suggests that, although there are more similarities than differences, there is value in breaking down the relationship by vegetation cover.

The spatial and temporal analyses show that downscaled SIF functions as a reasonable spatial and temporal proxy for GPP, across multiple timescales and vegetation covers. The figures show that regions and vegetation-climate categories with high correlation in one spatio-temporal analysis generally show high correlation in another analysis, suggesting that spatial and temporal correlation in the $\mathrm{SIF}_{\mathrm{DS}}-\mathrm{GPP}_{\mathrm{FX}}$ datasets are actually interlinked. The highest correlations are almost exclusively found between between $\mathrm{SIF}_{\mathrm{DS}}$ and $\mathrm{GPP}_{\mathrm{FX}}$ within the same growing season as a result of the strong effect of seasonality in the key environmental drivers of primary productivity, such as radiation, temperature and water availability. Indeed, all vegetationclimate categories except for equatorial broadleaf forests exhibit $r>50 \%$, with all regions outside the tropics and the arid grasslands of central Australia showing high correlation.

The spatial correlation and the temporal trend between years show similar features, though are generally weaker than the intra-annual correlation, with some regions of tropical rainforest and continental forest in Russia displaying anti-correlation. There is also a wider distribution in the strength of the $\mathrm{SIF}_{\mathrm{DS}}-\mathrm{GPP}_{\mathrm{FX}}$ correlation. This is despite the fact that the temporal analyses have a more granular level of spatial detail, with each pixel more susceptible to fluctuations. This is particularly true of the inter-annual comparison, which uses fewer data points in the regression. 
https://doi.org/10.5194/bg-2021-354

Preprint. Discussion started: 21 January 2022

(c) Author(s) 2022. CC BY 4.0 License.

(c) (i)
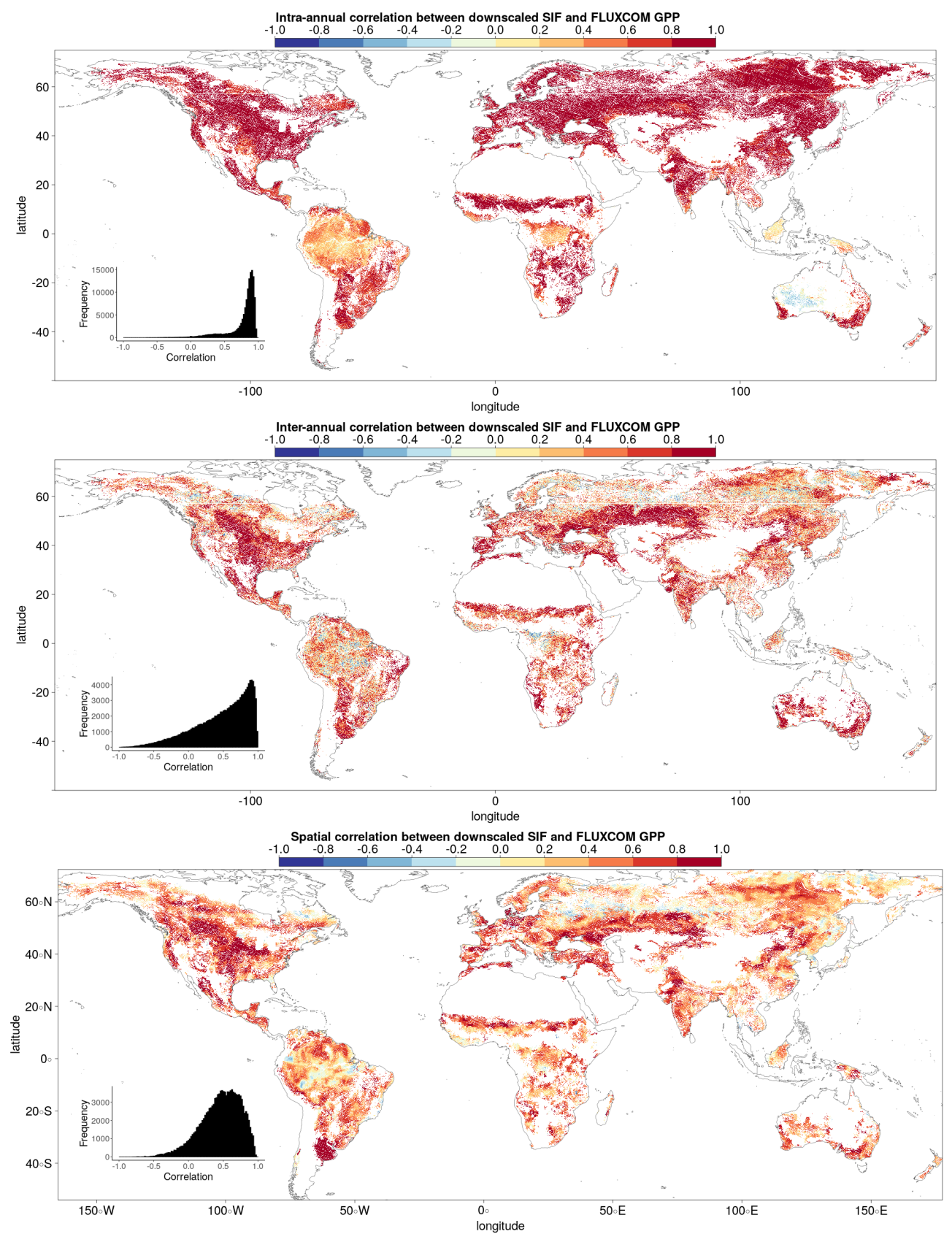

Figure 3. The Pearson's correlation coefficient, $r$, for: Above: the intra-annual temporal relationship between the downscaled SIF and FLUXCOM GPP over 8-day timesteps within a growing season. Middle: the inter-annual temporal relationship between the mean annual downscaled SIF and mean annual FLUXCOM GPP. Below: the spatial relationship between the mean annual downscaled SIF and mean annual FLUXCOM GPP, with the correlation determined for a given dominant vegetation cover and climate zone over a $2.5^{\circ}$ moving window. 
https://doi.org/10.5194/bg-2021-354

Preprint. Discussion started: 21 January 2022

(c) Author(s) 2022. CC BY 4.0 License.

(c) (i)



Figure 4. The Pearson's correlation coefficient, $r$, between downscaled SIF and FLUXCOM GPP for the spatial relationship, intra-annual temporal relationship within a growing season, and the inter-annual temporal trend across years. For the spatial analysis, a single global spatial correlation is calculated for each vegetation cover and climate zone, whilst the temporal relationships display the median global correlation and $25 \%$ upper and lower quantiles for each pixel, broken down by vegetation cover and climate zone.

\subsection{The spatial linear relationship between SIF $_{\mathrm{DS}}$ and $\mathrm{GPP}_{\mathrm{FX}}$}

Figure 5 shows the relative distribution and spatial linear relationship between the mean growing season FLUXCOM GPP as a function of the respective mean values of the downscaled SIF during the growing season. The data are broken down into separate categories depending on the Köppen-Geiger climate grouping and dominant vegetation cover of the pixel.

The significant substructure in the $\mathrm{SIF}_{\mathrm{DS}}-\mathrm{GPP}_{\mathrm{FX}}$ distribution and greater deviation from the linearity in the 'ALL' categories, give evidence to the fact that the $\mathrm{SIF}_{\mathrm{DS}}-\mathrm{GPP}_{\mathrm{FX}}$ spatial relationship response is dependent on both the climate and vegetation 


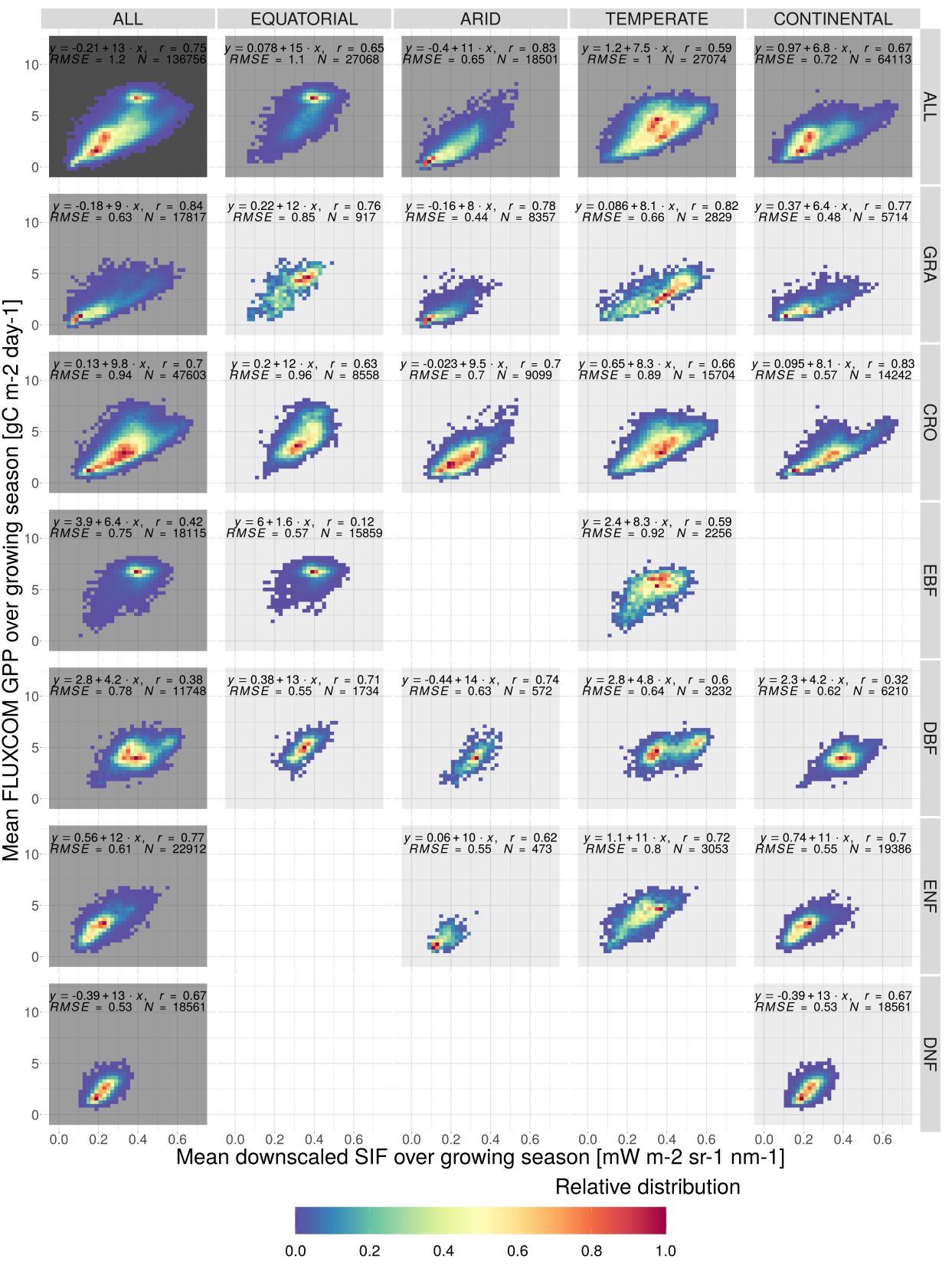

Figure 5. The spatial relationship between the mean growing season downscaled SIF and FLUXCOM GPP, broken down into separate Köppen-Geiger climate zones and vegetation cover categories. The plot shows the frequency distribution of pixels into $\mathrm{SIF}_{\mathrm{DS}}-\mathrm{GPP}_{\mathrm{FX}}$ bins, relative to the highest frequency bin in that category. A black dashed line representing a linear model in each category is overlaid and compared to a grey dotted line representing a linear model produced without the breakdown into separate categories (i.e. 'ALL-ALL'). The linear model equation, correlation coefficient $r$, root mean squared error (RMSE) and number of pixels are included. 
https://doi.org/10.5194/bg-2021-354

Preprint. Discussion started: 21 January 2022

(c) Author(s) 2022. CC BY 4.0 License.

\section{(c) (i)}

covers. There is also some evidence that there is a slight trend towards a reduction in the slope in cooler climates, though this may result from factors other than the climate itself, for example, differences in the spatial distribution of vegetation between evergreen and deciduous types or between $\mathrm{C} 3$ and $\mathrm{C} 4$ crops and grasses.

In all categories except EBF, the spatial correlations are comparable to the relationship observed between FLUXCOM GPP and SIF measurements from the OCO-2 instrument, as seen in Sun et al. (2018) confirming the overall value of the downscaled SIF product for this specific exercise. In this study, the following correlation coefficients are exhibited (broken down by biome): $r_{\mathrm{GRA}}=0.74 ; r_{\mathrm{CRO}}=0.88 ; r_{\mathrm{EBF}}=0.74 ; r_{\mathrm{DBF}}=0.8 ; r_{\mathrm{NF}}=0.84$ (needleleaf). The differences to this study may result from the selection criteria of the biomes, the singular grouping of vegetation covers across different climate zones, and the forcing of the linear relationship intercept through zero. In particular, the latter assumption of the SIF-GPP relationship leads to higher correlation coefficients compared to the case when the intercept may float.

We acknowledge that, in some categories, a linear model may be too simplistic to represent the relationship between SIF $_{\mathrm{DS}}$ and $\mathrm{GPP}_{\mathrm{FX}}$. This is more true for the woody plants which display some complexity in the $\mathrm{SIF}_{\mathrm{DS}}-\mathrm{GPP}_{\mathrm{FX}}$ relationship, in contrast to herbaceaous vegetation, which remains highly linear, despite exhibiting a greater range in values. The clearest deviation from linearity is found in highly productive equatorial evergreen forests, where a wide range of spatio-temporal variation in SIF $_{\mathrm{DS}}$ is observed, while a considerably smaller variability is reproduced in the modelled $\mathrm{GPP}_{\mathrm{FX}}$. This non-linearity is explored in more depth in the discussion.

Whilst at first glance the heatmap of temperate deciduous broadleaf forests similarly hints at a plateau effect, the figure can in fact be divided into two areas of high $\mathrm{SIF}_{\mathrm{DS}}$ and low $\mathrm{SIF}_{\mathrm{DS}}$ data points corresponding to separate spatial locations. The lower $\mathrm{SIF}_{\mathrm{DS}}$ values correspond to deciduous forests in Southern Africa and South America, whilst the higher SIF $_{\mathrm{DS}}$ values occur in North America and Europe, suggesting that there may not be global universality in the $\mathrm{SIF}_{\mathrm{DS}}-\mathrm{GPP}_{\mathrm{FX}}$ relationship, or that different types of deciduous broadleaf forests found in distinct regions could respond differently, possibly based on differences in species composition.

\subsection{Spatial analysis of covariance between SIF $_{\mathrm{DS}}$ and GPP FX $_{\text {S }}$}

340 The results of the analysis of covariance between pairs of vegetation covers within a climate zone, are shown in table 1 through the p-value and $\eta^{2}$ for the slope and intercept of the linear relationship. It should be noted that the ANCOVA analysis assumes linearity between $\mathrm{SIF}_{\mathrm{DS}}$ and $\mathrm{GPP}_{\mathrm{FX}}$, which is present in most vegetation covers, with noted exceptions. In each climate category, vegetation cover pairs with the largest $\eta^{2}$ for the slope are listed first, where the slope is significant (p-value $<0.05$ ). If differences in the regression slope are not significant (i.e. the slopes are considered to be parallel), then the difference in the size of the effect of the intercept is considered, such that the lowest ranked pairs within a climate zone are the most similar in their $\mathrm{SIF}_{\mathrm{DS}}-\mathrm{GPP}_{\mathrm{FX}}$ response.

The ANCOVA results in equatorial regions show that the categorisation by vegetation class is not a significant factor in the slope-dependence of the $\mathrm{SIF}_{\mathrm{DS}}-\mathrm{GPP}_{\mathrm{FX}}$ for all vegetation types except evergreen broadleaf forests, which, as discussed, exhibits non-linearity in the $\mathrm{SIF}_{\mathrm{DS}}-\mathrm{GPP}_{\mathrm{FX}}$ relationship. Differing intercepts between the DBF and the herbaceous vegetation covers, however, suggest that whilst the $\mathrm{SIF}_{\mathrm{DS}}-\mathrm{GPP}_{\mathrm{FX}}$ relationship scales in similar ways between vegetation covers, there 


\begin{tabular}{|c|c|c|c|c|c|c|}
\hline \multirow[b]{2}{*}{ Climate } & \multicolumn{2}{|c|}{ land cover } & \multicolumn{2}{|c|}{ slope } & \multicolumn{2}{|c|}{ intercept } \\
\hline & $\mathrm{LC}_{1}$ & $\mathrm{LC}_{2}$ & p-value & $\eta^{2}$ & p-value & $\eta^{2}$ \\
\hline Equatorial & EBF & $\mathrm{DBF}$ & $1.34 \times 10^{-95}$ & 0.19 & $<1.00 \times 10^{-99}$ & 0.53 \\
\hline Equatorial & $\mathrm{EBF}$ & GRA & $1.59 \times 10^{-77}$ & 0.17 & $<1.00 \times 10^{-99}$ & 0.49 \\
\hline Equatorial & $\mathrm{EBF}$ & $\mathrm{CRO}$ & $1.85 \times 10^{-55}$ & 0.12 & $<1.00 \times 10^{-99}$ & 0.49 \\
\hline Equatorial & $\mathrm{DBF}$ & $\mathrm{CRO}$ & $1.53 \times 10^{-01}$ & $<0.01$ & $3.91 \times 10^{-45}$ & 0.10 \\
\hline Equatorial & DBF & GRA & $1.36 \times 10^{-01}$ & $<0.01$ & $1.37 \times 10^{-39}$ & 0.09 \\
\hline Equatorial & GRA & $\mathrm{CRO}$ & $8.38 \times 10^{-01}$ & $<0.01$ & $5.09 \times 10^{-01}$ & $<0.01$ \\
\hline Arid & GRA & $\mathrm{DBF}$ & $4.35 \times 10^{-28}$ & 0.07 & $<1.00 \times 10^{-99}$ & 0.36 \\
\hline Arid & CRO & $\mathrm{DBF}$ & $3.01 \times 10^{-10}$ & 0.02 & $6.88 \times 10^{-91}$ & 0.23 \\
\hline Arid & $\mathrm{DBF}$ & $\mathrm{ENF}$ & $4.64 \times 10^{-06}$ & 0.02 & $1.75 \times 10^{-05}$ & 0.02 \\
\hline Arid & GRA & $\mathrm{CRO}$ & $1.41 \times 10^{-04}$ & 0.01 & $3.14 \times 10^{-36}$ & 0.08 \\
\hline Arid & GRA & $\mathrm{ENF}$ & $1.00 \times 10^{-03}$ & 0.01 & $6.46 \times 10^{-79}$ & 0.21 \\
\hline Arid & ENF & $\mathrm{CRO}$ & $6.36 \times 10^{-01}$ & $<0.01$ & $4.27 \times 10^{-05}$ & $<0.01$ \\
\hline Temperate & DBF & ENF & $4.09 \times 10^{-56}$ & 0.12 & $3.08 \times 10^{-08}$ & 0.02 \\
\hline Temperate & $\mathrm{DBF}$ & GRA & $5.80 \times 10^{-39}$ & 0.08 & $<1.00 \times 10^{-99}$ & 0.50 \\
\hline Temperate & $\mathrm{DBF}$ & $\mathrm{CRO}$ & $2.36 \times 10^{-23}$ & 0.05 & $5.81 \times 10^{-86}$ & 0.18 \\
\hline Temperate & $\mathrm{EBF}$ & $\mathrm{DBF}$ & $1.80 \times 10^{-19}$ & 0.04 & $<1.00 \times 10^{-99}$ & 0.20 \\
\hline Temperate & ENF & GRA & $1.77 \times 10^{-12}$ & 0.02 & $1.00 \times 10^{-99}$ & 0.56 \\
\hline Temperate & ENF & $\mathrm{CRO}$ & $6.22 \times 10^{-08}$ & 0.02 & $<1.00 \times 10^{-99}$ & 0.27 \\
\hline Temperate & $\mathrm{EBF}$ & ENF & $2.33 \times 10^{-07}$ & 0.01 & $2.25 \times 10^{-42}$ & 0.09 \\
\hline Temperate & $\mathrm{EBF}$ & GRA & $9.52 \times 10^{-01}$ & $<0.01$ & $1.00 \times 10^{-99}$ & 0.68 \\
\hline Temperate & $\mathrm{EBF}$ & $\mathrm{CRO}$ & $9.14 \times 10^{-01}$ & $<0.01$ & $<1.00 \times 10^{-99}$ & 0.47 \\
\hline Temperate & GRA & $\mathrm{CRO}$ & $8.28 \times 10^{-01}$ & $<0.01$ & $1.55 \times 10^{-63}$ & 0.13 \\
\hline Continental & $\mathrm{DBF}$ & DNF & $5.72 \times 10^{-54}$ & 0.11 & $1.71 \times 10^{-07}$ & 0.01 \\
\hline Continental & DNF & GRA & $3.77 \times 10^{-49}$ & 0.10 & $<1.00 \times 10^{-99}$ & 0.25 \\
\hline Continental & $\mathrm{DBF}$ & $\mathrm{ENF}$ & $4.57 \times 10^{-43}$ & 0.09 & $9.59 \times 10^{-11}$ & 0.02 \\
\hline Continental & ENF & GRA & $1.27 \times 10^{-34}$ & 0.07 & $<1.00 \times 10^{-99}$ & 0.60 \\
\hline Continental & DNF & $\mathrm{CRO}$ & $1.54 \times 10^{-26}$ & 0.06 & $9.95 \times 10^{-62}$ & 0.13 \\
\hline Continental & $\mathrm{DBF}$ & $\mathrm{CRO}$ & $9.06 \times 10^{-23}$ & 0.05 & $<1.00 \times 10^{-99}$ & 0.21 \\
\hline Continental & ENF & $\mathrm{CRO}$ & $8.43 \times 10^{-15}$ & 0.03 & $<1.00 \times 10^{-99}$ & 0.42 \\
\hline Continental & $\mathrm{DBF}$ & GRA & $1.66 \times 10^{-11}$ & 0.02 & $<1.00 \times 10^{-99}$ & 0.30 \\
\hline Continental & GRA & $\mathrm{CRO}$ & $2.66 \times 10^{-09}$ & 0.02 & $4.24 \times 10^{-14}$ & 0.03 \\
\hline Continental & ENF & DNF & $9.18 \times 10^{-05}$ & 0.01 & $<1.00 \times 10^{-99}$ & 0.32 \\
\hline
\end{tabular}

Table 1. Analysis of covariance between pairs of land covers in different Köppen-Geiger climate groupings. ANCOVA is only performed on the intercept when the difference between slopes is not considered significant. In order to highlight areas of similarity and difference, the $\eta^{2}$ column, comparable to the percentage of the difference in the slope or intercept (the latter assuming equivalence of the slopes) attributable to the vegetation cover, is coloured green, yellow and red for the slope categories: $\leq 0.01,0.02-0.05,>0.05$; and the intercept categories: $\leq 0.01,0.02-0.15,>0.15$, respectively. 
https://doi.org/10.5194/bg-2021-354

Preprint. Discussion started: 21 January 2022

(c) Author(s) 2022. CC BY 4.0 License.

(c) (i)

may be differences in the starting potential. Linear relationships in grass and cropland are statistically indistinguishable, whilst around $10 \%$ of the sum of squares between DBF and CRO/GRA intercepts can be attributed to the vegetation classification. In equatorial broadleaf forests $12-19 \%$ of the difference in the $\mathrm{SIF}_{\mathrm{DS}}-\mathrm{GPP}_{\mathrm{FX}}$ scaling can be attributed to the categorisation, and therefore when using SIF as a proxy for productivity, EBF should clearly be considered separately from other vegetation classes.

In arid climates the difference between the slopes of vegetation covers is significant for all except the ENF-CRO pair. However, there is little to distinguish the $\mathrm{SIF}_{\mathrm{DS}}-\mathrm{GPP}_{\mathrm{FX}}$ scaling by vegetation categories, with less than $2 \%$ of the sum of squares attributable to the vegetation covers for all except GRA-DBF (7\%). If the assumption is made that the vegetation categorisation has no effect on the $\mathrm{SIF}_{\mathrm{DS}}-\mathrm{GPP}_{\mathrm{FX}}$ slope, and that the slopes can be considered parallel between vegetation covers, then the intercepts generally distinguish between the woody and non-woody vegetation covers, with crossover in CROENF. Between the ENF-DBF intercepts, $2 \%$ of the sum of squares is attributable to the vegetation cover, whilst the proportion is $8 \%$ for GRA-CRO. Mixing between herbaceous and woody covers, on the other hand, and the proportion of the sum of squares attributable to the vegetation cover is between $21-36 \%$, with the exception of ENF-CRO, which are statistically almost indistinguishable.

In temperate regions the only major distinction in the gradient of the $\mathrm{SIF}_{\mathrm{DS}}-\mathrm{GPP}_{\mathrm{FX}}$ relationship between vegetation covers is found in deciduous broadleaf forests $(4-12 \%)$. As discussed in the previous section, temperate DBF is dominated by two distinct Northern and Southern hemisphere clusters with differing $\mathrm{SIF}_{\mathrm{DS}}-\mathrm{GPP}_{\mathrm{FX}}$ relationships, which results in a distinct and separate linear relationship. Regarding the other vegetation covers, assuming that the categorisation is of little importance to the slope, accounting for $\leq 2 \%$ of the sum of squares, and that the slopes could be considered parallel between the vegetation covers, the differences in the intercept broadly divide along the lines of woody and herbaceous species. The sum of squares attributable to differences in the intercept are: woody-woody, $9 \%$; herbaceous-herbaceous, $13 \%$; woody-herbaceous, $27-68 \%$.

Finally, in continental climates, ENF and DNF species exhibit a similar $(<1 \%) \mathrm{SIF}_{\mathrm{DS}}-\mathrm{GPP}_{\mathrm{FX}}$ scaling (though a much larger difference attributable to the intercept $30 \%)$ and are somewhat distinct from the other vegetation species $(6-11 \%)$, with the exception of CRO-ENF (3\%). Within these other vegetation species, $<5 \%$ of the difference in the $\mathrm{SIF}_{\mathrm{DS}}-\mathrm{GPP}_{\mathrm{FX}}$ slope can be attributed to the choice of vegetation cover and, assuming the null hypothesis for the slope, the intercept again distinguishes between the herbaceous plants (GRA-CRO, 3\%) and mixed, herbaceous-woody (DBF-CRO, 21\%; DBF-GRA, 30\%).

Overall, the ANCOVA analysis suggests that there is a large similarity in the scaling of the $\mathrm{SIF}_{\mathrm{DS}}-\mathrm{GPP}_{\mathrm{FX}}$ response (i.e. the slope) between vegetation covers, with the major exceptions of temperate deciduous broadleaf forests, continental needleaf forests, and, particularly, tropical evergreen forests. In terms of the scaling of the $\mathrm{SIF}_{\mathrm{DS}}-\mathrm{GPP}_{\mathrm{FX}}$ slope, these three vegetation covers may be treated as being reasonably distinct, with at least around $5 \%$ and up to $20 \%$ of the difference between slopes being attributable to the vegetation classification. Amongst the other species where the slope does not distinguish between vegetation covers so prominently (with generally less than $3 \%$ of the slope variation attributable to the vegetation categorisation), the intercept, and therefore the systemic difference between the linear relationships, loosely depends on whether the species is woody or herbaceous, with higher values for woody species. The difference in the $\mathrm{SIF}_{\mathrm{DS}}-\mathrm{GPP}_{\mathrm{FX}}$ response between cropland 
https://doi.org/10.5194/bg-2021-354

Preprint. Discussion started: 21 January 2022

(c) Author(s) 2022. CC BY 4.0 License.

\section{(c) (i)}

and grassland is particularly minor. A caveat must be made that there are some exceptions to these generalisations, and there is no statistically concrete global distinction between groupings of vegetation covers.

These results offer loose quantitative support for the larger trends observed in figure 5, and demonstrate that whilst there are broad similarities in the $\mathrm{SIF}_{\mathrm{DS}}-\mathrm{GPP}_{\mathrm{FX}}$ response between different vegetation types, there are still distinctions that can be made based on the background climate conditions. A loose, possible grouping of vegetation covers may be suggested within the climate zones, whereby equatorial regions feature: herbaceous (CRO+GRA), EBF and DBF groups; arid regions feature: herbaceous and woody (DBF+ENF) groups; temperate regions feature: herbaceous, woody (ENF+EBF) and DBF groups; and continental regions feature: herbaceous, DBF, ENF, DNF groups. This reduces the climate-vegetation categories for which we expect differing $\mathrm{SIF}_{\mathrm{DS}}-\mathrm{GPP}_{\mathrm{FX}}$ responses from 18 groups to 12 overall.

\subsection{Estimating the global spatial distribution of GPP with downscaled SIF}

The mean growing season downscaled SIF can be projected into an estimate of growing season GPP using the global linear relationships for each climate and vegetation cover category displayed in figure 5. The absolute and percentage difference of

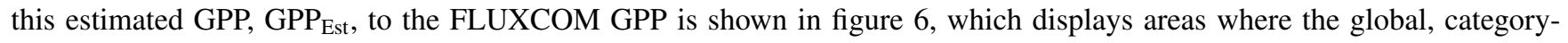
dependent, linear relationship shows positive or negative biases in replicating the $\mathrm{GPP}_{\mathrm{FX}}$ from the local $\mathrm{SIF}_{\mathrm{DS}}$ observations. The figures are created using three different versions of the global spatial linear relationships between $\mathrm{SIF}_{\mathrm{DS}}$ and GPP $\mathrm{FX}_{\text {. In the }}$ first instance, four separate linear relationships are derived for the four different climate zones. In the second instance the linear relationships are derived separately for each climate zone and vegetation cover, with 18 separate $\mathrm{SIF}_{\mathrm{DS}}-\mathrm{GPP}_{\mathrm{FX}}$ relationships. Finally, separate linear relationships are derived in each climate zone for each the different vegetation groupings suggested by the results of the analysis of covariance, with 12 groups overall.

The figures show that there is added value for GPP prediction in breaking down the relationship into the differing vegetation covers since the SIF-GPP relationship is not climate and vegetation invariant. When only the Köppen-Geiger climate grouping is used to classify the spatial $\mathrm{SIF}_{\mathrm{DS}}-\mathrm{GPP}_{\mathrm{FX}}$ relationships, there is a significantly greater difference between the FLUXCOM GPP and the GPP estimated from the downscaled SIF, compared to when vegetation cover is taken into account. As may be expected, the vegetation covers flagged as particularly distinguished in their spatio-temporal $\mathrm{SIF}_{\mathrm{DS}}-\mathrm{GPP}_{\mathrm{FX}}$ response, such as equatorial evergreen forests and continental needleleaf forests, especially suffer from this lack of a breakdown. The similarity in the lower figures, where the $\mathrm{SIF}_{\mathrm{DS}}-\mathrm{GPP}_{\mathrm{FX}}$ scaling depends on the grouping suggested by the analysis of covariance, compared to the unique vegetation covers in the middle figures, show that whilst vegetation cover appears to be an important parameter in classifying $\mathrm{SIF}_{\mathrm{DS}}-\mathrm{GPP}_{\mathrm{FX}}$ relationships, it is possible to combine vegetation groups in a way that doesn't noticeably affect the $\mathrm{SIF}_{\mathrm{DS}}-\mathrm{GPP}_{\mathrm{FX}}$ scaling. It should be noted that vegetation cover here may be a proxy for other variables, such as local conditions, soil type or a refined climate grouping, and in this sense further investigation in similar, localised conditions is required.

415 Figure 7 shows the global gross primary production estimated from the downscaled SIF and the $\mathrm{SIF}_{\mathrm{DS}}-\mathrm{GPP}_{\mathrm{FX}}$ relationships between vegetation groupings suggested by the ANCOVA results. It is particularly notable that in equatorial rainforests, the flat linear relationship derived between $\mathrm{SIF}_{\mathrm{DS}}-\mathrm{GPP}_{\mathrm{FX}}$ results in estimated GPP values with low variation. 
https://doi.org/10.5194/bg-2021-354

Preprint. Discussion started: 21 January 2022

(c) Author(s) 2022. CC BY 4.0 License.

(c) (i)
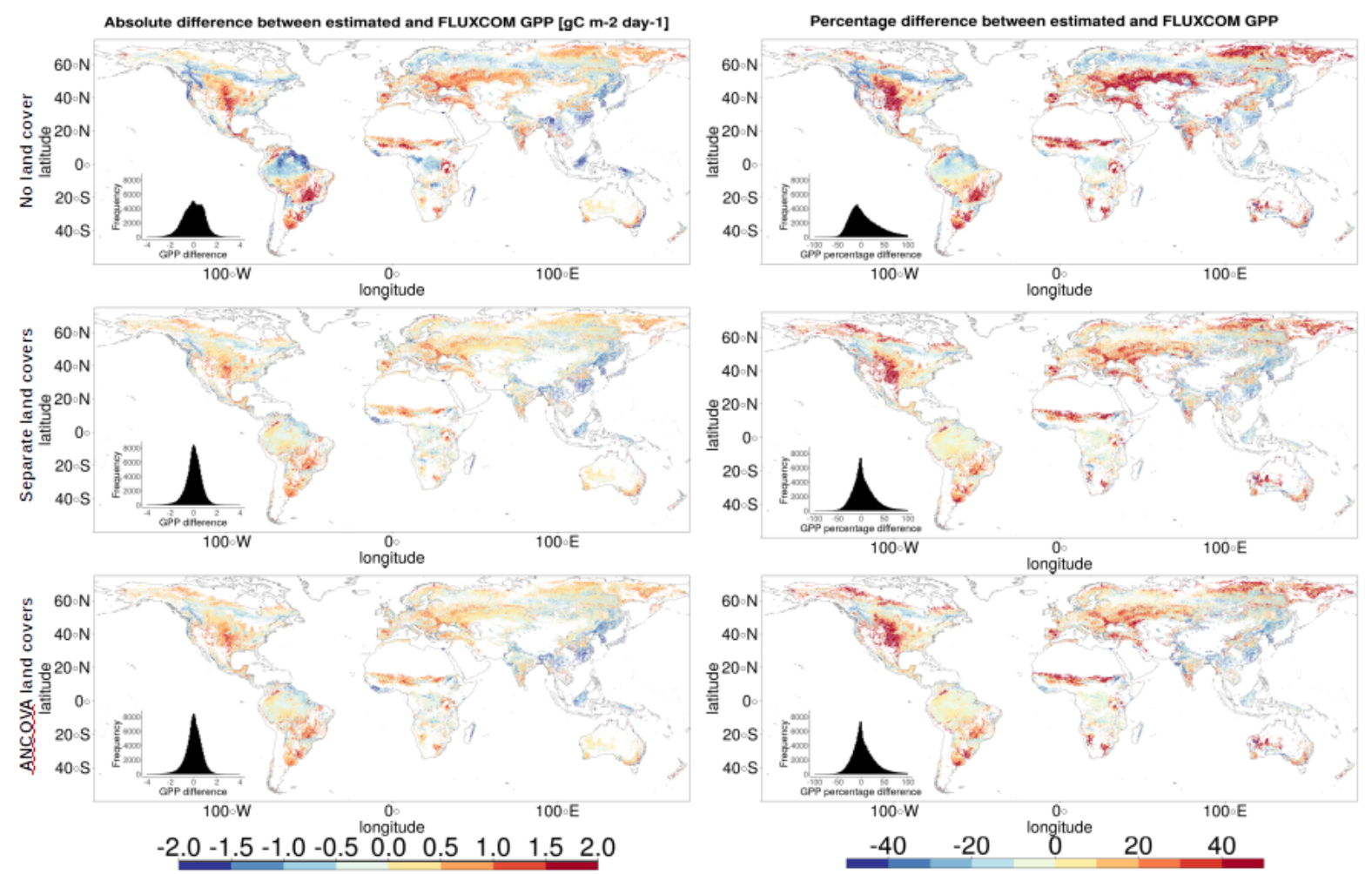

Figure 6. The absolute (left) and percentage (right) difference between the mean annual estimated primary production, GPP ${ }_{\text {Est }}$ and the mean annual FLUXCOM GPP. GPP Est is estimated by projecting the downscaled SIF at each pixel using SIF $_{\mathrm{DS}}-\mathrm{GPP}_{\mathrm{FX}}$ relationships derived within: top, each climate zone; middle, each vegetation cover within each climate zone; bottom, different climate-vegetation groupings suggested by the analysis of covariance.

\subsection{The SIF $_{D S}$ response to meteorological fluctuations}

Figure 8 shows the average $\mathrm{z}$-score of the $\mathrm{SIF}_{\mathrm{DS}}$ with respect to the z-score of the four meteorological variables considered in this study as environmental drivers of primary productivity. Each bin contains multiple data points (at least five in order to be displayed) with the $\mathrm{SIF}_{\mathrm{DS}} \mathrm{Z}$-score taken as the average of the data points within the bin. The figure shows how anomalies in monthly values of climate drivers - relative to the 'average' conditions for that month - are related to fluctuations in SIF $_{\mathrm{DS}}$. The figures are broken down into the same categorisation as in the previous study, clearly showing that in the various climates, vegetation covers respond differently, and sometimes in opposing directions, to climate drivers depending on the limiting factor of photosynthesis (e.g. water scarcity, low temperatures, etc). Equivalent figures for the FLUXCOM GPP can be found in appendix A1.

Figure 9 shows the average $\mathrm{SIF}_{\mathrm{DS}}$ and $\mathrm{GPP}_{\mathrm{FX}} \mathrm{z}$-scores as a function of the corresponding $\mathrm{z}$-score of the four meteorological variables. The figure uses the exact data that is input into figure 8 , and categorises the temperature, VPD, soil moisture and solar radiation z-score of pixels from the long-term monthly mean into 10 groups between -2.5 and +2.5 . The median corre- 
https://doi.org/10.5194/bg-2021-354

Preprint. Discussion started: 21 January 2022

(c) Author(s) 2022. CC BY 4.0 License.

(c) (i)

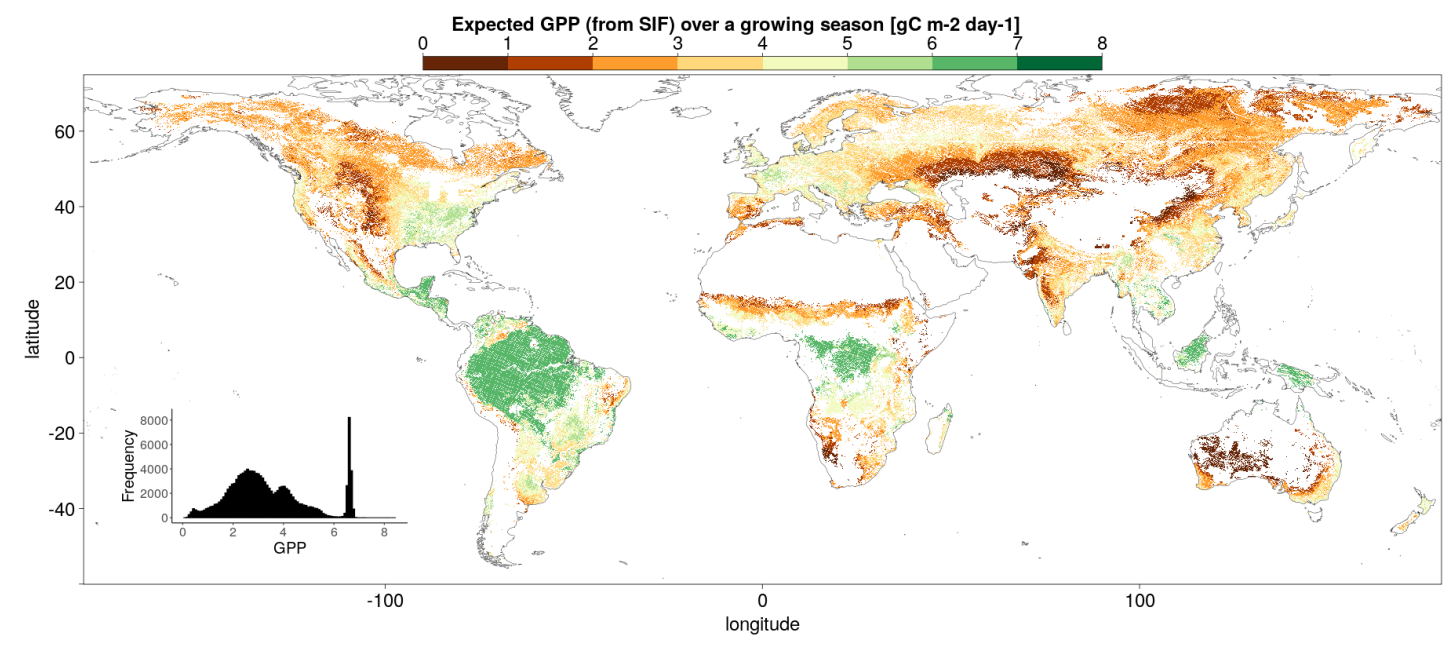

Figure 7. The global GPP estimated from the downscaled SIF and the $\mathrm{SIF}_{\mathrm{DS}}-\mathrm{GPP}_{\mathrm{FX}}$ spatial linear relationships between vegetation groupings suggested from the results of the analysis of covariance.

sponding $\mathrm{SIF}_{\mathrm{DS}}$ and $\mathrm{GPP}_{\mathrm{FX}} \mathrm{Z}$-scores, relative to the long-term monthly mean of each pixel, are shown for each meteorological variable. The results are broken down by the Köppen-Geiger climate and vegetation cover groupings discussed previously. The figure therefore shows the average $\mathrm{SIF}_{\mathrm{DS}}$ and $\mathrm{GPP}_{\mathrm{FX}}$ fluctuations that correspond to a given fluctuation in each meteorological condition, and can be used to interpret the meteorological drivers that may result in fluctuations in vegetation productivity.

The first point to note is that the link between $\operatorname{SIF}_{\mathrm{DS}}$ and meteorological fluctuations is more significant in some climate/vegetation cover categories than others. The $\mathrm{SIF}_{\mathrm{DS}}$ from grasslands and croplands responds in a very similar manner across all climates, but often differs from the response of woody vegetation. The $\mathrm{SIF}_{\mathrm{DS}}$ and $\mathrm{GPP}_{\mathrm{FX}}$ together respond in a similar way to the meteorological fluctuations, with the $\mathrm{GPP}_{\mathrm{FX}}$ generally more responsive, particularly in the case of woody vegetation. This is likely caused by the inclusion of meteorological information in the FLUXCOM GPP product, resulting in a correlation and so over-sensitivity. Whilst the SIF $_{\mathrm{DS}}$ may be less sensitive in general, unlike the FLUXCOM model it also captures information relating to the physiology of the plant, potentially bringing extra information into consideration when determining vegetation response.

Clear and expected trends in the $\mathrm{SIF}_{\mathrm{DS}}$ data can be picked out. For example, plants in cooler climates respond more positively to higher temperature fluctuations and plants in arid climates benefit significantly from soil moisture and reduced VPD (more humid conditions). Arid and continental climates, which in general are often harsher environments for plant life, exhibit a larger meteorological dependence than equatorial and temperate ones, whilst herbaceous plants are generally also more weather dependent. As the $\mathrm{SIF}_{\mathrm{DS}}$ response is measured with respect to conditions in an average month, the response often differs between Köppen-Geiger climates, for example, DBF and ENF forests respond positively to VPD (drier air) in temperate and continental climates but negatively in tropical and arid climates. 
https://doi.org/10.5194/bg-2021-354

Preprint. Discussion started: 21 January 2022

(c) Author(s) 2022. CC BY 4.0 License.
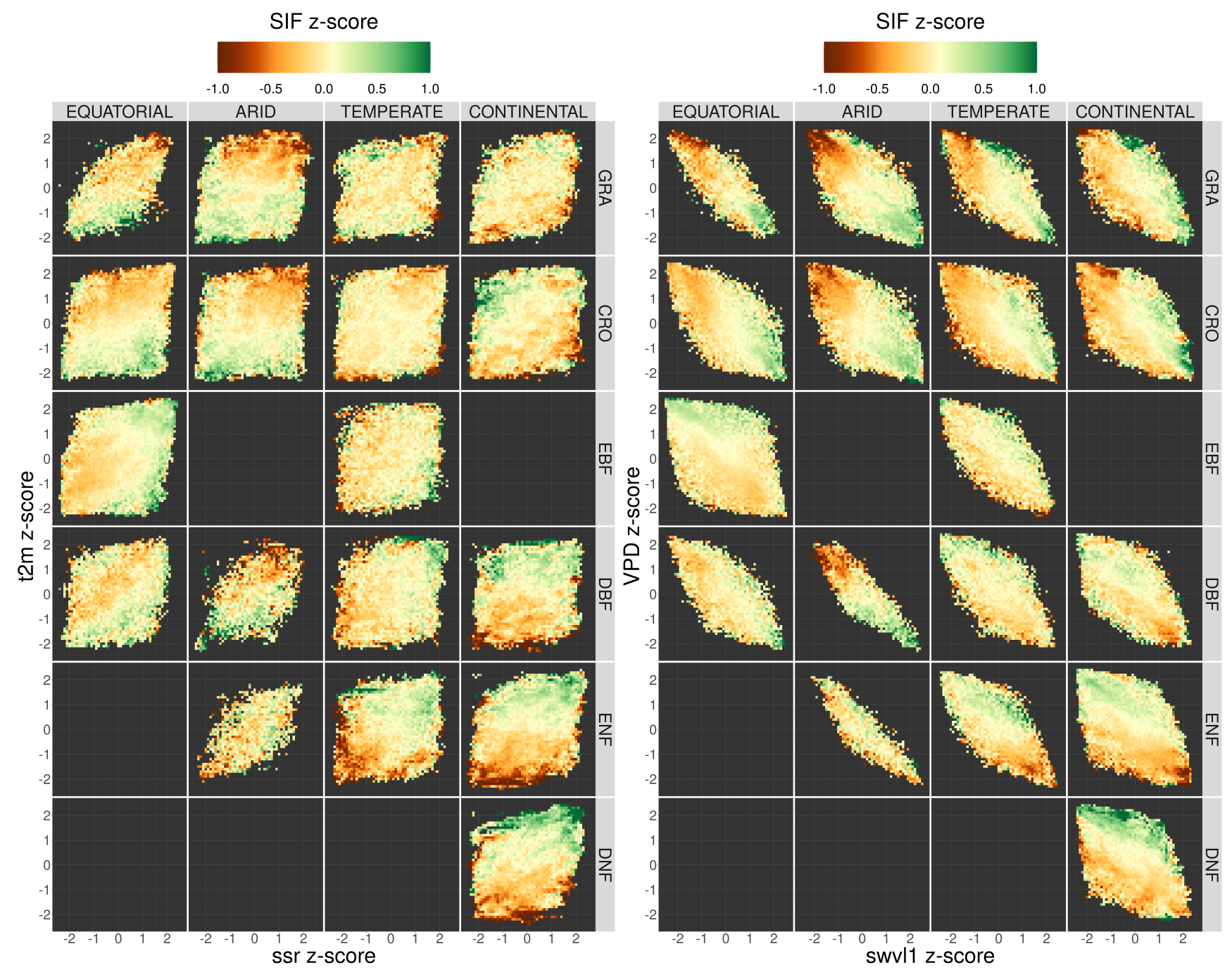

Figure 8. The relationship between fluctuations in meteorological variables and the corresponding fluctuations in the measured downscaled SIF. The fluctuations are measured relative to the monthly mean for each pixel and expressed as a z-score. The four meteorological variables are air temperature and net surface solar radiation ( $\mathrm{t} 2 \mathrm{~m}$ and ssr, left) and vapour pressure deficit and soil moisture (VPD and swvl1, right). The $\mathrm{SIF}_{\mathrm{DS}}$ response in each bin is the mean of all data points in each bin of meteorological z-score. The data is broken down into separate Köppen-Geiger climate zones and land cover categories.

The response of $\mathrm{SIF}_{\mathrm{DS}}$ to fluctuations in the meteorological variables is not always of simple interpretation since there may be co-limitation from multiple drivers linked by complex correlation patterns. In figure 8, co-limitation is observed where the direction of the $\mathrm{SIF}_{\mathrm{DS}}$ response lies along the diagonal, for example the preference for both high temperatures and high levels of radiation in temperate deciduous broadleaf forests, or for condition of low VPD and high soil moisture content in grassland 


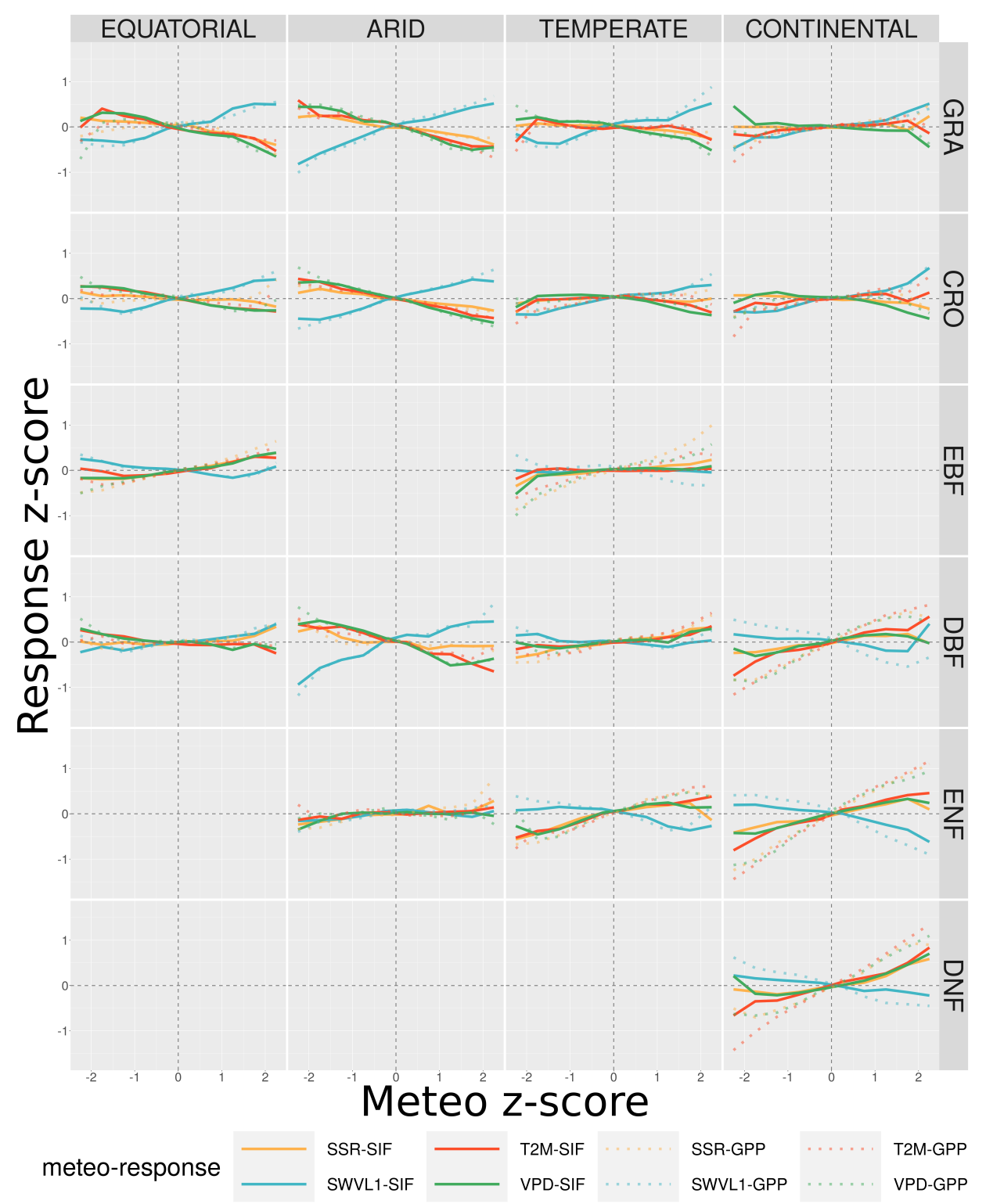

Figure 9. The average fluctuation in the remotely-sensed downscaled SIF and FLUXCOM GPP, as a function of the fluctuation in several meteorological variables. The fluctuations are defined in terms of the z-score of each variable, calculated for 10 different bins between -2.5 and 2.5, and the corresponding median $\mathrm{SIF}_{\mathrm{DS}} / \mathrm{GPP}_{\mathrm{FX}} \mathrm{Z}$-score, relative to the long-term (2007-2014) monthly mean for each pixel (each pixel may contribute multiple months within the growing season). The meteorological variables considered from the Copernicus Climate Service (C3S) Climate Data Store (CDS) and are: surface net solar radiation (SSR), air temperature (T2M), vapour pressure deficit (VPD) and soil moisture (SWVL1). The data is broken down into separate Köppen-Geiger climate zones and land cover categories. 
https://doi.org/10.5194/bg-2021-354

Preprint. Discussion started: 21 January 2022

(c) Author(s) 2022. CC BY 4.0 License.

(c) (i)

and croplands. Strong correlation is noticeable in the $\mathrm{SIF}_{\mathrm{DS}}$ response to meteorological fluctuations, as can be seen clearly in equatorial rainforests in figure 9: high VPD correlates with high cloud cover, limiting the solar radiation arriving at the leaves and, naturally, reducing temperatures and affecting rainfall (and therefore soil moisture). Meanwhile, the correlation between

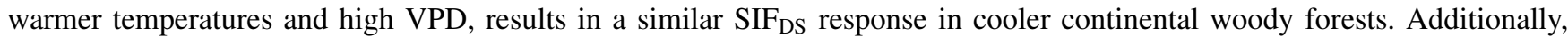
differences and sub-patterns in the $\mathrm{SIF}_{\mathrm{DS}}$-meteorological response may be complicated by the spatial distribution of plant species, which is not captured by the broad Köppen-Geiger categorisation. For example equatorial EBF forests may be located in wetter environments than Equatorial DBF forests, and therefore profit from differing fluctuations in the local climate, in this case a lower soil moisture and higher VPD.

Figure 9 shows that the strength of the relationship between the $\operatorname{SIF}_{\mathrm{DS}}$ fluctuations and the meteorological fluctuations generally increases for more extreme deviations of $\mathrm{SIF}_{\mathrm{DS}}$. For example, in continental deciduous needleleaf forests, a two standard deviation increase in the temperature (relative to the long-term mean for that month) corresponds to a $\mathrm{SIF}_{\mathrm{DS}}$ that is an average of 0.8 standard deviations higher than usual. In comparison, a smaller temperature fluctuation of between 1 and 1.5 standard deviations above the monthly mean temperature would correspond to a slightly lower increase in the SIF (+0.3 standard devations above the monthly mean). The results therefore provide evidence that not only do fluctuations in meteorological conditions correspond to fluctuations in SIF, but more extreme fluctuations often result in more extreme fluctuations in SIF. In this context the study suggests that it is possible to use high-resolution SIF as a near-real time measure of the resilience of ecosystems to climate fluctuations. For example, evergreen broadleaf forests appear to show relatively little deviation in SIF up to reasonably extreme weather fluctuations. It is important to note though, that 'extreme fluctuations' here are measured relative to a location's average climate variation, which may be small in absolute terms compared to other categories. As the climate categorisation considered in this study is relatively broad, further research of using high resolution SIF on specific ecosystems is required.

Finally, the results are used to determine the driving and limiting climate variables on a global scale. Figure 10 shows a map of the meteorological variable corresponding to the highest and lowest average SIF fluctuation.

\section{Discussion}

\subsection{The use of downscaled SIF be used as a proxy for GPP: does it add value?}

The study demonstrates the utility of the Duveiller et al. (2020) downscaling method in providing a robust, high-resolution SIF dataset that can be used as proxy for gross primary production. This method uses a light-use efficiency modelling based approach to establish a relationship between SIF and higher resolution remote sensing variables. The resulting high resolution $\mathrm{SIF}_{\mathrm{DS}}$ benefits the analysis in enabling higher purity selections in the vegetation classification of pixels, and therefore more precision when assessing the different dynamics and patterns of the relationships between SIF $_{\mathrm{DS}}$ and $\mathrm{GPP}_{\mathrm{FX}}$ across different vegetation covers and climate regions. A high level of spatio-temporal correlation is found across almost all Köppen-Geiger climate and vegetation groupings, comparable to levels observed between non-downscaled SIF and FLUXCOM GPP. Breaking down the correlations into their separate constituent vegetation covers shows diversity in the $\mathrm{SIF}_{\mathrm{DS}}-\mathrm{GPP}_{\mathrm{FX}}$ relationship, and 
https://doi.org/10.5194/bg-2021-354

Preprint. Discussion started: 21 January 2022

(c) Author(s) 2022. CC BY 4.0 License.

(c) (i)
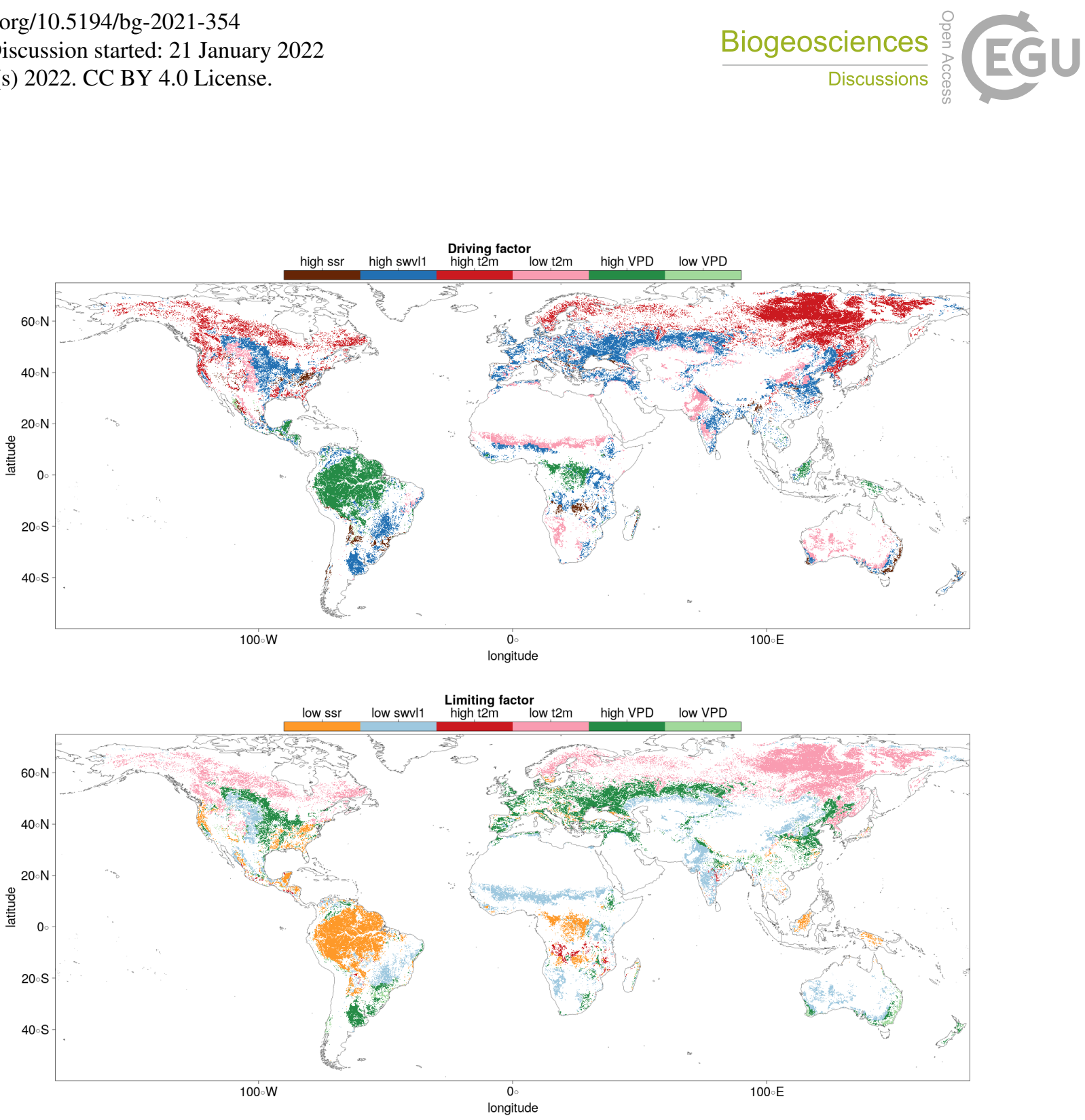

Figure 10. The driving (above) and limiting (below) meteorological conditions displayed at a globe scale. The driving and limiting variables are those that respectively correspond to the largest upward and downward fluctuations in downscaled SIF for each Köppen-Geiger climatevegetation grouping.

therefore that there is some dependence on vegetation cover in the relationship between canopy-level SIF and vegetation productivity. For the most part, the downscaled SIF reproduces the spatial patterns observed in the FLUXCOM GPP data, for example in figure 2, and scales linearly, with a few notable exceptions.

The clear response of $\mathrm{SIF}_{\mathrm{DS}}$ to meteorological fluctuations of key climatic drivers shows that it is possible to observe the temporal patterns and anomalies of vegetation productivity and stress remotely, via satellite. This suggests the possibility of using SIF in the near-real-time monitoring of vegetation stress in reaction to environmental conditions. As climates change it becomes increasingly important to know how vegetation responds to both long-term trends in the climate as well as increasingly frequent extreme weather events. 
https://doi.org/10.5194/bg-2021-354

Preprint. Discussion started: 21 January 2022

(c) Author(s) 2022. CC BY 4.0 License.

\section{(c) (i)}

The reproduction of known SIF-GPP patterns using the downscaled SIF demonstrates its utility as a high-resolution proxy of primary productivity. The use of the downscaling method on recent and future retrievals of SIF, such as the high-resolution retrievals from the TROPOMI satellite instrument, will enable further study on the relationship between SIF and GPP. Furthermore, the current downscaled SIF dataset provides an archive at a comparable resolution for the analysis of trends across longer timescales.

\subsection{Areas of divergence between SIF $_{\mathrm{DS}}$ and $\mathrm{GPP}_{\mathrm{FX}}$}

Figure 2 shows a clear divergence between the most productive areas in terms of FLUXCOM GPP, the equatorial rainforests of Brazil, central Africa and Indonesia, and the regions with the highest levels of downscaled SIF, the croplands of the mid-West, Western Europe and South America.

Equatorial broadleaf forests are also areas with reduced spatio-temporal correlation between $\mathrm{SIF}_{\mathrm{DS}}$ and $\mathrm{GPP}_{\mathrm{FX}}$, as seen in figure 3, with some areas anti-correlated. Figure 5 shows that the high variance in downscaled SIF is not matched by the similarly wide variation in FLUXCOM GPP observed in other vegetation types resulting in a flat relationship. This may hint at a saturation at high values of $\mathrm{GPP}_{\mathrm{FX}}$, whereby the observed $\mathrm{SIF}_{\mathrm{DS}}$ increases without a corresponding increase in $\mathrm{GPP}_{\mathrm{FX}}$ at the same rate. Such a plateau, particularly in evergreen broadleaf forests, could be driven by the saturation of the fraction of absorbed photosynthetically active radiation at high LAI values or perhaps by constraints in the GPP $\mathrm{FX}_{\text {model. Indeed the }}$ largest uncertainty in the FLUXCOM dataset is found in the tropics, an area with limited FLUXNET sites, and a similarly low correlation has been observed between $\mathrm{SIF}_{\mathrm{DS}}$ and $\mathrm{GPP}_{\mathrm{FX}}$ on a seasonal scale (Jung et al., 2020). A similar, if slightly reduced, plateau in the spatial $\mathrm{SIF}_{\mathrm{DS}}-\mathrm{GPP}_{\mathrm{FX}}$ relationship in evergreen needleleaf forests supports evidence of non-linearity in the temporal relationship found in Kim et al. (2021), similarly attributed to $\mathrm{GPP}_{\mathrm{FX}}$ saturation (as measured via an eddy covariance system) with absorbed photosynthetically active radiation.

The comparatively higher values of $\mathrm{SIF}_{\mathrm{DS}}$ in productive farm-belts supports evidence, such as in Guanter et al. (2014), that SIF-based crop productivity estimates are higher than other GPP estimates. The distribution of C3 and C4 crops may play a role here, as demonstrated by Zhang et al. (2017), which finds an underestimation of the FLUXCOM GPP in cropland areas, in addition to an overestimation in tropical rainforests. It may therefore be the case that the downscaled SIF is more sensitive to C3/C4 differences than the FLUXCOM GPP model. Additionally some studies, such as He et al. (2020), show more linearity between SIF and GPP in C4 crops, compared to C3 crops, with GPP estimated by eddy covariance towers. Differences in crop cover impacting the $\mathrm{SIF}_{\mathrm{DS}}-\mathrm{GPP}_{\mathrm{FX}}$ scaling may also be seen in figure 6. For example, in East Asia, there is an under-estimate of productivity based on the global $\mathrm{SIF}_{\mathrm{DS}}-\mathrm{GPP}_{\mathrm{FX}}$ relationship, and local measurements of downscaled SIF, whilst there is an over-estimate in the Americas, Africa and Europe.

The divergences between $\mathrm{SIF}_{\mathrm{DS}}$ and $\mathrm{GPP}_{\mathrm{FX}}$ may partially be attributed to the procedures used to collect and model the input data, however the divergences also support growing evidence of physiological reasons for the $\mathrm{SIF}_{\mathrm{DS}}-\mathrm{GPP}_{\mathrm{FX}}$ differences. This suggests that downscaled SIF could provide added value to the FLUXCOM estimate of the GPP in certain regions where the characterization of vegetation based on FaPAR and functional types in the machine learning framework is not sufficient to capture the spatio-temporal pattern of primary productivity. 
https://doi.org/10.5194/bg-2021-354

Preprint. Discussion started: 21 January 2022

(c) Author(s) 2022. CC BY 4.0 License.

(c) (i)

\subsection{The universality of the $\mathrm{SIF}_{\mathrm{DS}}-\mathrm{GPP}_{\mathrm{FX}}$ relationship across vegetation covers}

Differences in the spatio-temporal $\mathrm{SIF}_{\mathrm{DS}}-\mathrm{GPP}_{\mathrm{FX}}$ correlation and linear relationship suggests that there is some deviation, on average, between vegetation covers. However, there is also substantial variability within vegetation groupings, meaning that for all except the clearest outliers, it is not possible to statistically distinguish between vegetation categories based on these deviations alone. Equatorial evergreen broadleaf forests clearly stand out as an outlier having a spatio-temporal $\mathrm{SIF}_{\mathrm{DS}^{-}}$ $\mathrm{GPP}_{\mathrm{FX}}$ relationship that is divergent from the other vegetation types and should be treated separately when projecting estimates of productivity from SIF, until the reasons for this divergence are fully accounted for. For the other vegetation covers with $\mathrm{SIF}_{\mathrm{DS}}-\mathrm{GPP}_{\mathrm{FX}}$ relationships that scale more linearly, there is no fixed $\eta^{2}$ threshold to categorically dictate when the vegetation categorisation plays an important role in distinguishing between the $\mathrm{SIF}_{\mathrm{DS}}-\mathrm{GPP}_{\mathrm{FX}}$ relationships. This is particularly true in cases where the difference in the slope is small $(\eta)$ but significant (p-value), whilst the difference in the intercept is large. However, the results of the ANCOVA provide evidence that some distinction can be made between the $\mathrm{SIF}_{\mathrm{DS}}-\mathrm{GPP}_{\mathrm{FX}} \mathrm{scaling}$ between certain categories of vegetation, like temperate deciduous broadleaf forests, continental needleaf forests, and tropical evergreen forests. Additionally, the intercept in the linear relationship tends to be slightly higher for woody trees compared to the herbaceous species and therefore a categorisation could loosely divide along this broad physiological plant trait.

Differences between vegetation covers likely result from differences is the canopy architecture and physiology, in particular the leaf clustering, chlorophyll content and maximum carboxylation capacity (Verrelst et al., 2015). This is particularly true for differences between herbaceaous and woody vegetation, where for the latter, the lower photon escape probability from the canopy results in a lower intensity of SIF for a given productivity. Additionally, as discussed previously, further disaggregation of vegetation covers may be beneficial, for example distinguishing between deciduous broadleaf forests in Northern and Southern hemispheres, and between C3/C4 vegetation. It is important to note however, that vegetation cover may partially be a proxy for other factors or regional variables, such as background climate conditions and soil properties. Distinctions between vegetation covers in the $\mathrm{SIF}_{\mathrm{DS}}$ response to meteorological stress shows the divide is broadly along these lines of woody vs non-woody vegetation types. Herbaceous plants are more susceptible to changes in water supply than woody species, universally preferring high soil moisture and low vapour pressure deficit in all environments. For woody trees, vapour pressure deficit tends to be more important than soil moisture, and plays very little role at all in the SIF $\mathrm{DS}_{\mathrm{DS}}$ response of tropical evergreen broadleaf forests. This highlights the importance of using soil moisture, in addition to VPD, in quantifying droughts, and in particular its impacts on herbaceous vegetation (Stocker et al., 2018). Additionally, herbaceous species tend to respond stronger to meteorological fluctuations, with the exception of needleleaf forests. Overall, the study shows that it is possible to draw a distinction in the $\mathrm{SIF}_{\mathrm{DS}}-\mathrm{GPP}_{\mathrm{FX}}$ and $\mathrm{SIF}_{\mathrm{DS}}$-meteorological relationships between vegetation covers. These loosely divide between woody and herbaceous vegetation, with particular cases where further investigation is needed to fully understand the relationship dynamics. 
https://doi.org/10.5194/bg-2021-354

Preprint. Discussion started: 21 January 2022

(c) Author(s) 2022. CC BY 4.0 License.

(c) (i)

\section{Conclusions}

560

This exploratory analysis confronts two of the most recent observation-based products that inform on the spatio-temporal variability of primary productivity at global scale, highlighting areas of coherence and divergence. Firstly, it demonstrates the utility of the Duveiller et al. (2020) downscaling method in providing a high-resolution SIF dataset that can be used as proxy for gross primary production for specific vegetation covers. Secondly, in highlighting areas of divergence, the study provides a remotely-sensed, independent comparison of downscaled SIF with the FLUXCOM GPP model. The relatively fine resolution of the downscaled SIF enables a global exploration of the spatio-temporal relationship between $\mathrm{SIF}_{\mathrm{DS}}$ and $\mathrm{GPP}_{\mathrm{FX}}$ at a level that distinguishes between differing vegetation cover types, enabling a categorisation of vegetation covers based on the $\mathrm{SIF}_{\mathrm{DS}}-\mathrm{GPP}_{\mathrm{FX}}$ response. For the most part, the gradient of the spatial $\mathrm{SIF}_{\mathrm{DS}}-\mathrm{GPP}_{\mathrm{FX}}$ response is similar between differing vegetation types, with the exceptions of temperate deciduous broadleaf forests, continental needleleaf forests and, particularly, equatorial broadleaf forests. However, the $\mathrm{GPP}_{\mathrm{FX}}$ systematic potential for a given $\mathrm{SIF}_{\mathrm{DS}}$ observation displays more variation between species, with some divergence between woody and non-woody plants. The study provides both evidence for the spatiotemporal correlation between downscaled SIF and FLUXCOM GPP, with different climate and vegetation covers exhibiting variability in the $\mathrm{SIF}_{\mathrm{DS}}-\mathrm{GPP}_{\mathrm{FX}}$ relationship. The temporal component of the $\mathrm{SIF}_{\mathrm{DS}}-\mathrm{GPP}_{\mathrm{FX}}$ relationship is generally stronger than the spatial component, in particular at an intra-annual scale. Regions of climate and vegetation cover exhibiting high spatial correlation between $\mathrm{SIF}_{\mathrm{DS}}$ and $\mathrm{GPP}_{\mathrm{FX}}$ also tend to exhibit higher temporal correlation, suggesting that the mechanisms driving spatial and temporal variability are similar. Vegetation in some climates, such as tropical rainforests, shows divergence from linearity in the $\mathrm{SIF}_{\mathrm{DS}}-\mathrm{GPP}_{\mathrm{FX}}$ relationship. Here the downscaled SIF data may provide additional, independent information to the FLUXCOM model, particularly at high GPP $_{\mathrm{FX}}$ values where the model may be at risk of saturation of photosynthetically active radiation.

The study also demonstrates the possibility of using near real-time satellite SIF measurements to study the response of vegetation to meteorological anomalies over short (monthly) timescales. Proving this technique at a global scale provides evidence for the use of high-resolution SIF in monitoring the resilience of local ecosystems to environmental fluctuations, an area of growing importance as extreme weather events become more frequent and more severe. Whilst there is similarity in the $\mathrm{SIF}_{\mathrm{DS}}-\mathrm{GPP}_{\mathrm{FX}}$ response between vegetation covers, there is more diversity between different vegetation covers in the $\mathrm{SIF}_{\mathrm{DS}}$ response to meteorological fluctuations, particularly between herbaceous species and woody trees.

The further collection of high-resolution SIF data via the downscaling method of Duveiller et al. (2020) in addition to satellites such as OCO-2 and the future FLEX mission, will continue aid the understanding of the relationship between SIF, environmental conditions and plant productivity, as well as the variety of response between vegetation covers. The benefit will be to advance our understanding and estimation of the Earth's productivity, on both a local and global level. 
https://doi.org/10.5194/bg-2021-354

Preprint. Discussion started: 21 January 2022

(c) Author(s) 2022. CC BY 4.0 License.

(c) (i)

\section{References}

590 Allan, R. and Pereira, L.: Crop evapotranspiration-Guidelines for computing crop water requirements-FAO Irrigation and drainage paper 56, vol. 56, 1998.

Anav, A., Friedlingstein, P., Beer, C., Ciais, P., Harper, A., Jones, C., Murray-Tortarolo, G., Papale, D., Parazoo, N., Peylin, P., Piao, S., Sitch, S., Viovy, N., Wiltshire, A., and Zhao, M.: Spatio-temporal patterns of terrestrial gross primary production: A review, Reviews of Geophysics, 53, https://doi.org/10.1002/2015RG000483, 2015.

Baldocchi, D., Falge, E., Gu, L., Olson, R., Hollinger, D., Running, S., Anthoni, P., Bernhofer, C., Davis, K., Evans, R., Fuentes, J., Goldstein, A., Katul, G., Law, B., Lee, X., Malhi, Y., Meyers, T., Munger, W., Oechel, W., U, K. T. P., Pilegaard, K., Schmid, H. P., Valentini, R., Verma, S., Vesala, T., Wilson, K., and Wofsy, S.: FLUXNET: A New Tool to Study the Temporal and Spatial Variability of Ecosystem-Scale Carbon Dioxide, Water Vapor, and Energy Flux Densities, Bulletin of the American Meteorological Society, 82, 2415 - 2434, https://doi.org/10.1175/1520-0477(2001)082<2415:FANTTS>2.3.CO;2, https://journals.ametsoc.org/view/journals/bams/82/11/ 1520-0477_2001_082_2415_fantts_2_3_co_2.xml, 2001.

Bowling, D. R., Garcia, M. R., Magney, T., Logan, B. A., Frankenberg, C., Grossman, K., Stutz, J., Raczka, B. M., Lopez, S., Burns, S. P., Blanken, P., and Lin, J. C.: Linkage between SIF and GPP in a seasonally-dormant high-elevation subalpine forest, in: AGU Fall Meeting Abstracts, vol. 2018, pp. B31N-2676, 2018.

CCI, E.: ESA: Land Cover CCI Product User Guide Version 2.0, http://maps.elie.ucl.ac.be/CCI/viewer/download/ESACCI-LC-Ph2-PUGv2_ 2.0.pdf, 2017.

Coppo, P., Taiti, A., Pettinato, L., Francois, M., Taccola, M., and Drusch, M.: Fluorescence Imaging Spectrometer (FLORIS) for ESA FLEX Mission, Remote Sensing, 9, 649, https://doi.org/10.3390/rs9070649, http://dx.doi.org/10.3390/rs9070649, 2017.

Defourny, P.: Land cover classification gridded maps from 1992 to present derived from satellite observations., https://doi.org/D3.3.11v1.0_PUGS_CDR_LC-CCI_v2.0.7cds_Products_v1.0., https://cds.climate.copernicus.eu/cdsapp\#!/dataset/satellite-land-cover?tab= 610 overview, 2019.

Didan, K., A. B.: NASA MEaSUREs Vegetation Index and Phenology (VIP) Phenology NDVI Yearly Global 0.05 CMG., https://doi.org/https://doi.org/10.5067/MEaSUREs/VIP/VIPPHEN_NDVI.004. Accessed 2020-01-31, 2016.

Duveiller, G. and Cescatti, A.: Spatially downscaling sun-induced chlorophyll fluorescence leads to an improved temporal correlation with gross primary productivity, Remote Sensing of Environment, 182, 72 - 89, https://doi.org/https://doi.org/10.1016/j.rse.2016.04.027, http: //www.sciencedirect.com/science/article/pii/S0034425716301936, 2016.

Duveiller, G., Filipponi, F., Walther, S., Köhler, P., Frankenberg, C., Guanter, L., and Cescatti, A.: A spatially downscaled suninduced fluorescence global product for enhanced monitoring of vegetation productivity, Earth System Science Data, 12, 1101-1116, https://doi.org/10.5194/essd-12-1101-2020, https://essd.copernicus.org/articles/12/1101/2020/, 2020.

Frankenberg, C. and Berry, J.: Solar Induced Chlorophyll Fluorescence: Origins, Relation to Photosynthesis and Retrieval, p. 143, https://doi.org/10.1016/B978-0-12-409548-9.10632-3, 2017.

Friedlingstein, P., Jones, M. W., O’Sullivan, M., Andrew, R. M., Hauck, J., Peters, G. P., Peters, W., Pongratz, J., Sitch, S., Le Quéré, C., Bakker, D. C. E., Canadell, J. G., Ciais, P., Jackson, R. B., Anthoni, P., Barbero, L., Bastos, A., Bastrikov, V., Becker, M., Bopp, L., Buitenhuis, E., Chandra, N., Chevallier, F., Chini, L. P., Currie, K. I., Feely, R. A., Gehlen, M., Gilfillan, D., Gkritzalis, T., Goll, D. S., Gruber, N., Gutekunst, S., Harris, I., Haverd, V., Houghton, R. A., Hurtt, G., Ilyina, T., Jain, A. K., Joetzjer, E., Kaplan, J. O., Kato, E., Klein Goldewijk, K., Korsbakken, J. I., Landschützer, P., Lauvset, S. K., Lefèvre, N., Lenton, A., Lienert, S., Lombardozzi, D., Marland, 
https://doi.org/10.5194/bg-2021-354

Preprint. Discussion started: 21 January 2022

(c) Author(s) 2022. CC BY 4.0 License.

\section{(c) (i)}

G., McGuire, P. C., Melton, J. R., Metzl, N., Munro, D. R., Nabel, J. E. M. S., Nakaoka, S.-I., Neill, C., Omar, A. M., Ono, T., Peregon, A., Pierrot, D., Poulter, B., Rehder, G., Resplandy, L., Robertson, E., Rödenbeck, C., Séférian, R., Schwinger, J., Smith, N., Tans, P. P., Tian, H., Tilbrook, B., Tubiello, F. N., van der Werf, G. R., Wiltshire, A. J., and Zaehle, S.: Global Carbon Budget 2019, Earth System Science Data, 11, 1783-1838, https://doi.org/10.5194/essd-11-1783-2019, https://www.earth-syst-sci-data.net/11/1783/2019/, 2019.

Gentine, P. and Alemohammad, H.: RSIF (Reconstructed Solar Induced Fluorescence): a machine-learning vegetation product based on MODIS surface reflectance to reproduce GOME-2 solar induced fluorescence, Geophysical Research Letters, 45, https://doi.org/10.1002/2017GL076294, 2018.

Grossiord, C., Buckley, T. N., Cernusak, L. A., Novick, K. A., Poulter, B., Siegwolf, R. T. W., Sperry, J. S., and McDowell, N. G.: Plant responses to rising vapor pressure deficit, New Phytologist, 226, 1550-1566, https://doi.org/https://doi.org/10.1111/nph.16485, https: //nph.onlinelibrary.wiley.com/doi/abs/10.1111/nph.16485, 2020.

Guanter, L., Zhang, Y., Jung, M., Joanna, J., Voigt, M., Berry, J., Frankenberg, C., Huete, A., Zarco-Tejada, P., Lee, J.-E., Moran, M., PonceCampos, G., Beer, C., Camps-Valls, G., Buchmann, N., Gianelle, D., Klumpp, K., Cescatti, A., Baker, J., and Griffis, T.: Global and time-resolved monitoring of crop photosynthesis with chlorophyll fluorescence, Proceedings of the National Academy of Sciences, p. 1, https://doi.org/10.1073/pnas.1320008111, 2014.

He, L., Magney, T., Dutta, D., Yin, Y., Köhler, P., Grossmann, K., Stutz, J., Dold, C., Hatfield, J., Guan, K., Peng, B., and Frankenberg, C.: From the Ground to Space: Using Solar-Induced Chlorophyll Fluorescence to Estimate Crop Productivity, Geophysical Research Letters, 47, e2020GL087 474, https://doi.org/https://doi.org/10.1029/2020GL087474, https://agupubs.onlinelibrary.wiley.com/doi/abs/10. 1029/2020GL087474, e2020GL087474 2020GL087474, 2020.

Jiao, W., Chang, Q., and Wang, L.: The Sensitivity of Satellite Solar-Induced Chlorophyll Fluorescence to Meteorological Drought, Earth's Future, 7, 558-573, https://doi.org/https://doi.org/10.1029/2018EF001087, https://agupubs.onlinelibrary.wiley.com/doi/abs/10. 1029/2018EF001087, 2019.

Joiner, J., Guanter, L., Lindstrot, R., Voigt, M., Vasilkov, A. P., Middleton, E. M., Huemmrich, K. F., Yoshida, Y., and Frankenberg, C.: Global monitoring of terrestrial chlorophyll fluorescence from moderate-spectral-resolution near-infrared satellite measurements: methodology, simulations, and application to GOME-2, Atmospheric Measurement Techniques, 6, 2803-2823, https://doi.org/10.5194/amt-6-28032013, https://www.atmos-meas-tech.net/6/2803/2013/, 2013.

Jung, M. and FLUXCOM Team: FLUXCOM (RS+METEO) Global Land Carbon Fluxes using CRUNCEP climate data, https://doi.org/10.17871/FLUXCOM_RS_METEO_CRUNCEPV6_1980_2013_V1, https://www.bgc-jena.mpg.de/geodb/FluxCom/RS_ METEO_CRUNCEPv6_1980_2013_v1.php, 2016.

Jung, M., Koirala, S., Weber, U., Ichii, K., Gans, F., Gustau-Camps-Valls, Papale, D., Schwalm, C., Tramontana, G., and Reichstein, M.: The FLUXCOM ensemble of global land-atmosphere energy fluxes, 2018.

Jung, M., Schwalm, C., Migliavacca, M., Walther, S., Camps-Valls, G., Koirala, S., Anthoni, P., Besnard, S., Bodesheim, P., Carvalhais, N., Chevallier, F., Gans, F., Goll, D. S., Haverd, V., Köhler, P., Ichii, K., Jain, A. K., Liu, J., Lombardozzi, D., Nabel, J. E. M. S., Nelson, J. A., O’Sullivan, M., Pallandt, M., Papale, D., Peters, W., Pongratz, J., Rödenbeck, C., Sitch, S., Tramontana, G., Walker, A., Weber, U., and Reichstein, M.: Scaling carbon fluxes from eddy covariance sites to globe: synthesis and evaluation of the FLUXCOM approach, Biogeosciences, 17, 1343-1365, https://doi.org/10.5194/bg-17-1343-2020, https://www.biogeosciences.net/17/1343/2020/, 2020.

Kim, J., Ryu, Y., Dechant, B., Lee, H., Kim, H. S., Kornfeld, A., and Berry, J. A.: Solar-induced chlorophyll fluorescence is nonlinearly related to canopy photosynthesis in a temperate evergreen needleleaf forest during the fall transition, Remote Sensing of 
https://doi.org/10.5194/bg-2021-354

Preprint. Discussion started: 21 January 2022

(c) Author(s) 2022. CC BY 4.0 License.

(c) (i)

Environment, 258, 112 362, https://doi.org/https://doi.org/10.1016/j.rse.2021.112362, https://www.sciencedirect.com/science/article/pii/ S0034425721000808, 2021.

Köhler, P., Guanter, L., and Joiner, J.: A linear method for the retrieval of sun-induced chlorophyll fluorescence from GOME-2 and SCIAMACHY data, Atmospheric Measurement Techniques, 8, 2589-2608, https://doi.org/10.5194/amt-8-2589-2015, https://www. atmos-meas-tech.net/8/2589/2015/, 2015.

Kottek, M., Grieser, J., Beck, C., Rudolf, B., and Rubel, F.: World Map of the Köppen-Geiger climate classification updated, Meteorologische Zeitschrift, 15, 259-263, https://doi.org/10.1127/0941-2948/2006/0130, http://dx.doi.org/10.1127/0941-2948/2006/0130, 2006.

Lee, J.-E., Frankenberg, C., van der Tol, C., Berry, J. A., Guanter, L., Boyce, C. K., Fisher, J. B., Morrow, E., Worden, J. R., Asefi, S., Badgley, G., and Saatchi, S.: Forest productivity and water stress in Amazonia: observations from GOSAT chlorophyll fluorescence, Proceedings of the Royal Society B: Biological Sciences, 280, 20130 171, https://doi.org/10.1098/rspb.2013.0171, https://royalsocietypublishing.org/ doi/abs/10.1098/rspb.2013.0171, 2013.

Li, X. and Xiao, J.: A Global, 0.05-Degree Product of Solar-Induced Chlorophyll Fluorescence Derived from OCO-2, MODIS, and Reanalysis Data, Remote Sensing, 11, 517, https://doi.org/10.3390/rs11050517, 2019.

Magney, T., Bowling, D., Logan, B., Grossmann, K., Stutz, J., Blanken, P., Burns, S., Cheng, R., Garcia, M., Köhler, P., Lopez, S., Parazoo, N., Raczka, B., Schimel, D., and Frankenberg, C.: Mechanistic evidence for tracking the seasonality of photosynthesis with solar-induced fluorescence, Proceedings of the National Academy of Sciences of the United States of America, 116, https://doi.org/10.1073/pnas.1900278116, 2019.

Magney, T. S., Barnes, M. L., and Yang, X.: On the Covariation of Chlorophyll Fluorescence and Photosynthesis Across Scales, Geophysical Research Letters, 47, e2020GL091 098, https://doi.org/https://doi.org/10.1029/2020GL091098, https://agupubs.onlinelibrary.wiley.com/ doi/abs/10.1029/2020GL091098, e2020GL091098 2020GL091098, 2020.

Muñoz Sabater, J., Dutra, E., Agustí-Panareda, A., Albergel, C., Arduini, G., Balsamo, G., Boussetta, S., Choulga, M., Harrigan, S., Hersbach, H., Martens, B., Miralles, D. G., Piles, M., Rodríguez-Fernández, N. J., Zsoter, E., Buontempo, C., and Thépaut, J.-N.: ERA5-Land: A state-of-the-art global reanalysis dataset for land applications, Earth System Science Data Discussions, 2021, 1-50, https://doi.org/10.5194/essd-2021-82, https://essd.copernicus.org/preprints/essd-2021-82/, 2021.

Muñoz Sabater, J.: ERA5-Land hourly data from 1981 to present., https://doi.org/10.24381/cds.e2161bac, https://cds.climate.copernicus.eu/ cdsapp\#!/dataset/reanalysis-era5-land?tab=overview, 2019a.

Muñoz Sabater, J.: ERA5-Land monthly averaged data from 1981 to present., https://doi.org/10.24381/cds.68d2bb3, https://cds.climate. copernicus.eu/cdsapp\#!/dataset/reanalysis-era5-land-monthly-means?tab=overview, 2019b.

Ploton, P., Mortier, F., Réjou-Méchain, M., Barbier, N., Picard, N., Rossi, V., Dormann, C., Cornu, G., Viennois, G., Bayol, N., Lyapustin, A., Gourlet-Fleury, S., and Pélissier, R.: Spatial validation reveals poor predictive performance of large-scale ecological mapping models, Nature Communications, 11, 4540, https://doi.org/10.1038/s41467-020-18321-y, https://doi.org/10.1038/s41467-020-18321-y, 2020.

Porcar-Castell, A., Tyystjärvi, E., Atherton, J., van der Tol, C., Flexas, J., Pfündel, E. E., Moreno, J., Frankenberg, C., and Berry, J. A.: Linking chlorophyll a fluorescence to photosynthesis for remote sensing applications: mechanisms and challenges, Journal of Experimental Botany, 65, 4065-4095, https://doi.org/10.1093/jxb/eru191, https://doi.org/10.1093/jxb/eru191, 2014.

Rubel, F. and Kottek, M.: Observed and projected climate shifts 1901-2100 depicted by world maps of the Köppen-Geiger climate classification, Meteorologische Zeitschrift, 19, 135-141, https://doi.org/10.1127/0941-2948/2010/0430, http://dx.doi.org/10.1127/0941-2948/ 2010/0430, 2010. 
https://doi.org/10.5194/bg-2021-354

Preprint. Discussion started: 21 January 2022

(c) Author(s) 2022. CC BY 4.0 License.

(c) (i)

Rubel, F., Brugger, K., Haslinger, K., and Auer, I.: The climate of the European Alps: Shift of very high resolution Köppen-Geiger climate zones 1800-2100, Meteorologische Zeitschrift, 26, 115-125, https://doi.org/10.1127/metz/2016/0816, 2017.

Running, S. W., Nemani, R. R., Heinsch, F. A., Zhao, M., Reeves, M., and Hashimoto, H.: A Continuous Satellite-Derived Measure of Global Terrestrial Primary Production, BioScience, 54, 547-560, https://doi.org/10.1641/0006-3568(2004)054[0547:ACSMOG]2.0.CO;2, https://doi.org/10.1641/0006-3568(2004)054[0547:ACSMOG]2.0.CO;2, 2004.

Ryu, Y., Berry, J., and Baldocchi, D.: What is global photosynthesis? History, uncertainties and opportunities, Remote Sensing of Environment, 223, 95-114, https://doi.org/10.1016/j.rse.2019.01.016, 2019.

Seneviratne, S.I., Nicholls, N., Easterling, D., Goodess, C., Kanae, S., Kossin, J., Luo, Y., Marengo, J., McInnes, K., andM. Reichstein, M. R., Sorteberg, A., Vera, C., , and Zhang, X.: Managing the Risks of Extreme Events and Disasters to Advance Climate Change Adaptation, A Special Report of Working Groups I and II of the Intergovernmental Panel on ClimateChange (IPCC). Cambridge University Press, Cambridge, UK, and New York, NY, USA,, Changes in climate extremes and their impacts on the naturalphysical environment, 109-230, https://www.ipcc.ch/site/assets/uploads/2018/03/SREX-Chap3_FINAL-1.pdf, 2012.

Stocker, B. D., Zscheischler, J., Keenan, T. F., Prentice, I. C., Peñuelas, J., and Seneviratne, S. I.: Quantifying soil moisture impacts on light use efficiency across biomes, New Phytologist, 218, 1430-1449, https://doi.org/https://doi.org/10.1111/nph.15123, https://nph. onlinelibrary.wiley.com/doi/abs/10.1111/nph.15123, 2018.

715 Sun, Y., Frankenberg, C., Jung, M., Joanna, J., Guanter, L., Köhler, P., and Magney, T.: Overview of Solar-Induced chlorophyll Fluorescence (SIF) from the Orbiting Carbon Observatory-2: Retrieval, cross-mission comparison, and global monitoring for GPP, Remote Sensing of Environment, 209, https://doi.org/10.1016/j.rse.2018.02.016, 2018.

Tramontana, G., Jung, M., Schwalm, C. R., Ichii, K., Camps-Valls, G., Ráduly, B., Reichstein, M., Arain, M. A., Cescatti, A., Kiely, G., Merbold, L., Serrano-Ortiz, P., Sickert, S., Wolf, S., and Papale, D.: Predicting carbon dioxide and energy fluxes across global FLUXNET sites with regression algorithms, Biogeosciences, 13, 4291-4313, https://doi.org/10.5194/bg-13-4291-2016, https://www.biogeosciences. net/13/4291/2016/, 2016.

Verrelst, J., Rivera, J. P., van der Tol, C., Magnani, F., Mohammed, G., and Moreno, J.: Global sensitivity analysis of the SCOPE model: What drives simulated canopy-leaving sun-induced fluorescence?, Remote Sensing of Environment, 166, 8-21, https://doi.org/https://doi.org/10.1016/j.rse.2015.06.002, https://www.sciencedirect.com/science/article/pii/S0034425715300328, 2015.

Walther, S., Duveiller, G., Jung, M., Guanter, L., Cescatti, A., and Camps-Valls, G.: Satellite Observations of the Contrasting Response of Trees and Grasses to Variations in Water Availability, Geophysical Research Letters, 46, 1429-1440, https://doi.org/https://doi.org/10.1029/2018GL080535, https://agupubs.onlinelibrary.wiley.com/doi/abs/10.1029/2018GL080535, 2019.

Yu, L., Wen, J., Chang, C., Frankenberg, C., and Sun, Y.: High Resolution Global Contiguous Solar-Induced Chlorophyll Fluorescence (SIF) of Orbiting Carbon Observatory-2 (OCO-2), Geophysical Research Letters, https://doi.org/10.1029/2018GL081109, 2018.

Zhang, Y., Guanter, L., Berry, J., Tol, C., Yang, X., Tang, J., and Zhang, F.: Model-based analysis of the relationship between suninduced chlorophyll fluorescence and gross primary production for remote sensing applications, Remote Sensing of Environment, 187, https://doi.org/10.1016/j.rse.2016.10.016, 2016.

Zhang, Y., Xiao, X., Wu, X., Zhou, S., Zhang, G., Qin, Y., and Dong, J. a.: A global moderate resolution dataset of gross primary production of vegetation for 2000-2016, Scientific Data, 4, 170 165, https://doi.org/10.1038/sdata.2017.165, https://doi.org/10.1038/sdata.2017.165, 2017.

Zhang, Y., Joanna, J., Alemohammad, H., Zhou, S., and Gentine, P.: A global spatially contiguous solar-induced fluorescence (CSIF) dataset using neural networks, Biogeosciences, 15, 5779-5800, https://doi.org/10.5194/bg-15-5779-2018, $2018 \mathrm{a}$. 
https://doi.org/10.5194/bg-2021-354

Preprint. Discussion started: 21 January 2022

(C) Author(s) 2022. CC BY 4.0 License.

(c) (1)

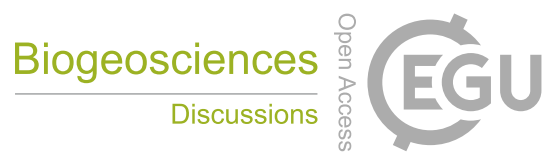

Zhang, Y., Joiner, J., Gentine, P., and Zhou, S.: Reduced solar-induced chlorophyll fluorescence from GOME-2 during Amazon drought caused by dataset artifacts, Global Change Biology, 24, 2229-2230, https://doi.org/10.1111/gcb.14134, https://onlinelibrary.wiley.com/ doi/abs/10.1111/gcb.14134, 2018b.

Álvaro Moreno-Martínez, Camps-Valls, G., Kattge, J., Robinson, N., Reichstein, M., van Bodegom, P., Kramer, K., Cornelissen, J. H. C., Reich, P., Bahn, M., Ülo Niinemets, Peñuelas, J., Craine, J. M., Cerabolini, B. E., Minden, V., Laughlin, D. C., Sack, L., Allred, B., Baraloto, C., Byun, C., Soudzilovskaia, N. A., and Running, S. W.: A methodology to derive global maps of leaf traits using remote sensing and climate data, Remote Sensing of Environment, 218, 69-88, https://doi.org/https://doi.org/10.1016/j.rse.2018.09.006, https: //www.sciencedirect.com/science/article/pii/S0034425718304176, 2018. 
https://doi.org/10.5194/bg-2021-354

Preprint. Discussion started: 21 January 2022

(c) Author(s) 2022. CC BY 4.0 License.

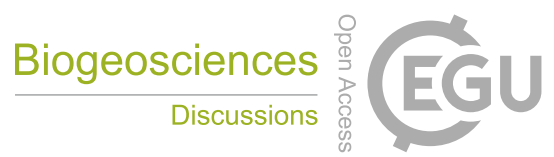

\section{Appendix A: Appendix}

\section{A1 FLUXCOM GPP response to meteorological fluctuations}
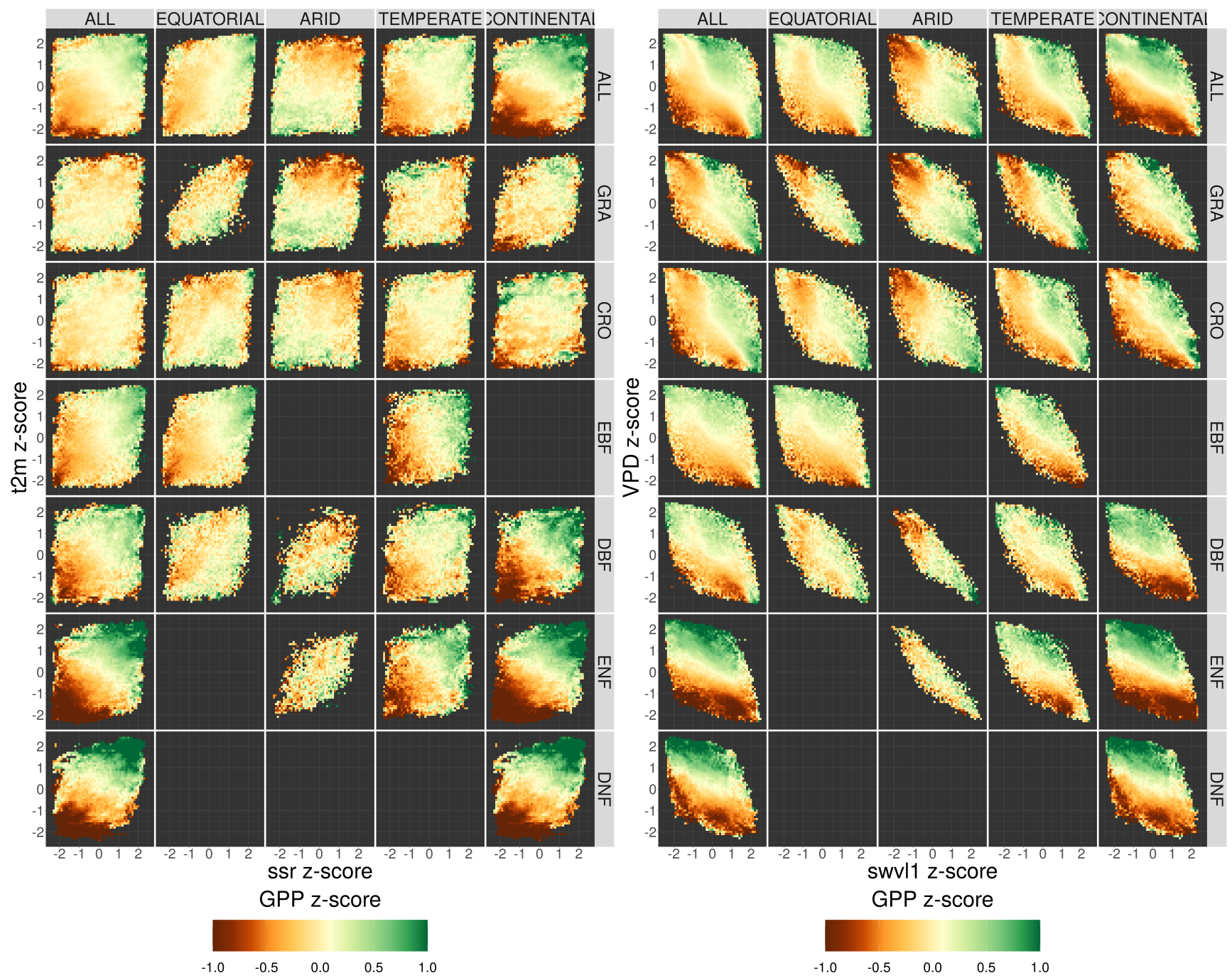

Figure A1. The relationship between fluctuations in meteorological variables and the corresponding fluctuations in the FLUXCOM GPP. The fluctuations are measured relative to the monthly mean for each pixel and expressed as a z-score. The four meteorological variables are air temperature and net surface solar radiation ( $\mathrm{t} 2 \mathrm{~m}$ and ssr, left) and vapour pressure deficit and soil moisture (VPD and swvl1, right).

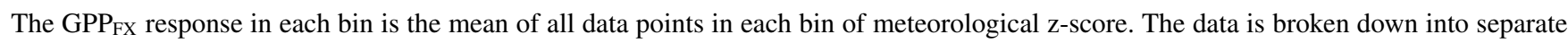
Köppen-Geiger climate zones and land cover categories. 